COMPLEX SPATIAL SKILLS: THE LINK BETWEEN VISUALIZATION AND CREATIVITY

\author{
by \\ April Diane Allen \\ Thesis submitted to the Faculty of the \\ Virginia Polytechnic Institute and State University \\ in partial fulfillment \\ of the requirements for the degree of
}

Master of Science

in

Housing, Interior Design and Resource Management

Joan H. McLain-Kark, Chair

Jeanette E. Bowker

Eric A. Wiedegreen

Bradley A. Whitney

September 3, 1999

Blacksburg, Virginia 


\title{
COMPLEX SPATIAL SKILLS: THE LINK BETWEEN VISUALIZATION AND CREATIVITY
}

\author{
by \\ April Diane Allen \\ Chair: Joan McLain-Kark \\ Housing, Interior Design and Resource Management
}

(ABSTRACT)

The purpose of this study was to determine if there is a correlation between spatial skills and creativity in interior design students.

Participants were subjects who took a visualization assessment and created the 33 projects used in the study, and 11 judges, professional design experts who rated the projects. The sample of subjects was comprised of interior design students at a FIDER-accredited institution in southwest Virginia. The judges included interior design educators and interior design graduate students having previous practice experience.

Subjects completed a pencil-and-paper Visualization Assessment consisting of 36 questions using two-dimensional and three-dimensional drawings (Isham, 1997). A percentage score for spatial skills was calculated for each subject based on the number of correct answers.

Design projects created by the students were assessed by subjective ratings on three Dimensions of Judgment taken from the Consensual Technique for Creativity Assessment (Barnard, 1992; Amabile, 1982). The three dimensions used in this study included Appropriateness, Creativity, and Novelty. Ratings were collected in two judging sessions at a local site. 
Interjudge reliabilities exceeded the established criterion level (.70 or greater) on all three dimensions, with coefficients ranging from .729 to .866 . Interjudge reliability for the Creativity dimension was .866 , indicating a high level of agreement among judges on creativity.

Intercorrelations among the dimensions indicated a high degree of association between the variables with Appropriateness and Novelty both significantly correlated with the Creativity dimension.

Pearson product-moment correlation was used to determine if there was a significant correlation between visualization and creativity in interior design students. No significant correlation was found. 


\section{ACKNOWLEDGEMENTS}

I wish to thank several individuals who were instrumental throughout the research process and writing of my thesis. First, I would like to thank my committee members for their continual support and encouragement: Dr. Joan McLain-Kark, Chair, who met with me regularly regardless of my level of preparation and helped me conceptualize the overall design of my study; Dr. Jeanette Bowker, who helped in numerous ways and gave invaluable assistance regarding the intricacies and the proper method of documenting research; Mr. Eric Wiedegreen for his insights into creativity research and helpful suggestions for presentation; and Mr. Bradley Whitney who offered his encouragement and belief in my ability to complete this study and permitted me to use his Presentations Technique class as participants.

Dr. Susan Barnard is owed a special debt of gratitude for the use of her thorough and insightful research, which a great deal of my study is based upon.

I wish to thank Dean Isham for his time and generosity in making his Visualization Assessment instrument available to me.

Special thanks are extended to my family for always being there and supporting me: My wonderful son, Charles, who is also in graduate school and commiserated with me; his lovely wife Rebecca for supporting his efforts; my siblings, Champ, Sherry, and Penny, who I know I can always count on to cheer for me; and to the memory of my parents who taught me to believe in myself and to create my own path in life. 


\section{TABLE OF CONTENTS}

Page

ABSTRACT . . . . . . . . . . . . . . . . . . . . ii

ACKNOWLEDGEMENTS . . . . . . . . . . . . . . .

LIST OF TABLES . . . . . . . . . . . . . . . . . . . . . vii

LIST OF FIGURES . . . . . . . . . . . . . . . . . . . . . viii

Chapter

I. INTRODUCTION . . . . . . . . . . . . . . . . . . . 1

Purpose of the Study . . . . . . . . . . . . . . . . . . 3

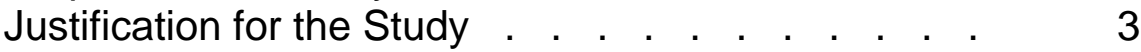

Limitations . . . . . . . . . . . . . . . . . . . . 4

II. REVIEW OF LITERATURE . . . . . . . . . . . . . 5

Visualization and Spatial Skills . . . . . . . . . . . . . $\quad 5$

Measurement of Spatial Skills/Visualization . . . . $\quad 6$

Creativity . . . . . . . . . . . . . . . . . . . . . . . 8

Measurement of Creativity. . . . . . . . . . . . . . 11

Link Between Spatial Skills and Creativity . . . . . 14

III. METHODOLOGY . . . . . . . . . . . . . . . . 18

Introduction . . . . . . . . . . . . . . . . . . . . . . 18

Subjects . . . . . . . . . . . . . . . . . . . . . . . . . 18

Visualization Assessment Instrument . . . . . . . . 18

Creativity Assessment Instrument . . . . . . . . . . 20

Judges . . . . . . . . . . . . . . . . . . . . . . 21

Procedures . . . . . . . . . . . . . . . . . . . 22

Project Creation Session . . . . . . . . . . . . . . . . . . . 23

Project Judging Sessions . . . . . . . . . . . . . . . . . . . 24

Physical Setting . . . . . . . . . . . . . . . . . . . . 24

Materials . . . . . . . . . . . . . . . . 24

Data Analysis . . . . . . . . . . . . . . . . . . . . . 25

IV. RESULTS AND DISCUSSION . . . . . . . . . . . . . 27 


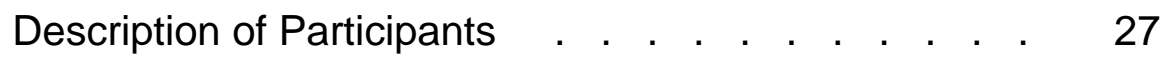

Subjects . . . . . . . . . . . . . . . . . . . . . 27

Judges . . . . . . . . . . . . . . . . . . . . . . . . . . . 28

Statistical Findings

Visualization Scores . . . . . . . . . . . . . . . . . . . 29

Creativity Ratings . . . . . . . . . . . . . . . . . . 29

Interjudge Reliability . . . . . . . . . . . . . . . . 29

Intercorrelations among Dimensions . . . . . . . 31

Correlation between Visualization and Creativity . . 31

Discussion of Findings . . . . . . . . . . . . . . . . . . . . . 38

V. SUMMARY AND CONCLUSIONS . . . . . . . . . . . 40

Summary . . . . . . . . . . . . . . . . . . 40

Recommendations/Discussion . . . . . . . . . . 42

Afterword. . . . . . . . . . . . . . . . . . . 43

REFERENCES CITED . . . . . . . . . . . . . . . . . . . . . . . . 44

\section{APPENDICES}

A. Permission to use Isham's Instrument . . . . . . . . . 47

B. Project Statement . . . . . . . . . . . . . . . . . 49

C Dimensions of Judgment for Interior Design Projects . . . 51

D Rating Sheets . . . . . . . . . . . . . . . . . . . 53

E Correspondence with Judges . . . . . . . . . . . . . 60

F Instructions for the Project Judging Session _ . . . . . . 63

G. Demographics Sheet . . . . . . . . . . . . . . . 65

H. Isham's Visualization Assessment _. . . . . . . . . . 67

I. Correlation Matrix . . . . . . . . . . . . . . . . . . . . . . 82

J. Representative Student Projects . . . . . . . . . . . 84

VITA . . . . . . . . . . . . . . . . . . . . . . . . . . 89 


\section{LIST OF TABLES}

Table

Page

1. Interjudge Realiabilities for Mean Scale Ratings on Dimensions of Judgment . . . . . . . . . . . . . . 30

2. Correlations of Visualization Scores with Creativity Scores . . . . . . . . . . . . . . . . . . . . . 34

3. Correlations of Adjusted Visualization Scores with Creativity Scores . . . . . . . . . . . . . . . . . 35 


\section{LIST OF FIGURES}

Figure

Page

1. Mean Creativity Score versus Mean

Appropriateness Score . . . . . . . . . . .

2. Mean Creativity Score versus Mean Novelty Score . . . . . . . . . . . . . . . . . . 33

3. Mean Creativity Score versus Visualization Score . . . . . . . . . . . . . . . . . .

4. Mean Creativity Score versus Adjusted Visualization Score . . . . . . . . . . . . . . . 


\section{CHAPTER I}

\section{INTRODUCTION}

Interior designers must be able to communicate their ideas to clients

verbally as well as visually. The visual communication is a way of expressing a graphic language for spatial thinking enabling the designer to represent an idea and to structure the idea through a shaping process. The client perceives the idea and judges it accordingly. "Visual perception is visual thinking" (Arnheim, 1969, p. 14).

In looking at an object we reach out for it. With an invisible finger we move through the space around us, go out to the distant places where things are found, touch them, catch them, scan their surfaces, trace their borders, explore their texture. It is an eminently active occupation. Impressed by this experience, early thinkers described the physical process of vision correspondingly. For example, Plato, in his Timaeus, asserts that the gentle fire that warms the human body flows out through the eyes in a smooth and dense stream of light. Thus a tangible bridge is established between the observer and the observed thing, and over this bridge the impulses of light that emanate from the object travel to the eyes and thereby to the soul (Arnheim, 1969, p. 19). Visualization is the manner of thought in which images are generated or recalled in the mind. These images may be manipulated, rotated, increased or 
decreased in size, or even transformed from one image into another. Spatial ability, which is closely related to visualization, emphasizes three-dimensional space. The two-dimensional image transforms to a mass or empty volume, providing a sense of proportion, distance, balance, and the like (West, 1997). Interior design students have little difficulty drawing graphically in plan to scale, yet they often experience difficulty transposing plan drawings into orthographic or perspective drawings both of which requires more complex spatial skills. The ability to visualize in the mind and communicate that conceptualization graphically are necessary components of design drawings.

During a study in the late 60s, Karlans, Schuerhoff, and Kaplan discovered a link between spatial skills and creativity in graduating architecture students (1969). The Cubes test, used to measure a spatial orientation factor, was found to be highly correlated with rated creativity. Both spatial skills and creativity are necessary for success in the field of architecture. If the same holds true for interior design students, the teaching of spatial skills will become even more important. Educational programs that fail to instill spatial skills in their students may be releasing graduates into the work environment who may never reach their potential as designers.

The Foundation for Interior Design Education Research (FIDER) states that interior design programs should "encourage innovation and creative approaches to design problem solving and show evidence of such approaches in the work and attitudes of students" (FIDER, 1993, p. 2). Creativity is one of the top competencies needed in entry-level positions by prospective employers of 
interior designers (Myers, 1982). In order to be successful in the design field, students should master the art of creative design solutions and the ability to think in creative ways. If spatial skills were correlated with creativity emphasis on the teaching of complex spatial skills would be one way to increase the creativity of design students.

\section{Purpose of the Study}

The purpose of this study is to determine if there is a correlation between spatial skills and creativity in interior design students. The research question to be answered is:

- Is there a correlation between spatial skills and creativity for interior design students?

Justification for the Study

Correlation of spatial skills with creativity for interior design students would emphasize the importance of teaching complex spatial skills to incoming freshmen at design schools. This could result in recognition of the increased significance of complex spatial skills for design students and further research into alternative methods of teaching these skills thus enhancing creativity. Visualization and visual transformations play an essential role into 'the way of seeing' design solutions.

A question arises as to which comes first, spatial skills or creativity. If a correlation is found between spatial skills and creativity, does that mean that spatial skills increase creativity, that creativity increases spatial skills, or both? 


\section{$\underline{\text { Limitations }}$}

This study is limited to interior design students at a southwest Virginia university. Generalization to the whole population of interior design may not be possible. It is limited to second year students and may not be generalized to all students in the program. Further study needs to take place to see if results could be replicated in design schools in other geographic regions of the country. 


\section{CHAPTER ॥}

\section{REVIEW OF LITERATURE}

This chapter will discuss spatial and visualization skills and how these skills can be measured. Next, creativity is defined with additional discussion on measures of creativity. Finally, the possible link between creativity and spatial skills is explored.

Visualization and Spatial Skills

Visualization and spatial skills are essential to interior designers, enabling them to communicate design solutions to their clients. Zavotka (1986) divided the components of spatial skills into the following categories: "1) mentally seeing two dimensional elements in a three dimensional surrounding, 2) visualizing the three dimensional environment from a two dimensional drawing, 3) mentally

rotating objects to another plane, and 4) visualizing objects in scale" (p. 45). The delivery of the designer's perception of the space through graphic communication is necessary to enable clients to experience a simulation of the finished product.

Psychologists believe that how we perceive spatially is not the perception of space but represents the relationship between objects in space. This is a learned phenomenon, and as we view distant objects, we see the intervening atmosphere and learn atmospheric perspective (things in the background appear lighter and smaller). We also learn height in plane, relative size, and focus. The eye cannot focus on two objects simultaneously thus helping the mind to distinguish a relationship between objects in space (McKim, 1972). 
Most objects in the environment are not viewed head-on, but obliquely. Circles become ellipses, and rectangles, trapezoids. As you walk, your viewpoint and each shape change. Some shapes become smaller, some larger. This is referred to as optical reality. Our perceptual reality adjusts the ever-changing images, providing object constancy. Perceptual reality combines what you know with the way you see (McKim, 1972).

When objects are perceived head-on, although they are rarely viewed this way, circles are seen as circles and rectangles as rectangles. The graphic method of drawing objects as seen head-on is orthographic projection. In theory an imaginary transparent box is placed over an object keeping the walls of the box parallel to the object. If you look perpendicularly through the side of the box you see one "true shape" of the object. The projection of the true shape onto the corresponding plane of the box is orthographic projection. Each side of the box can hold a 'true shape' view of the object. Flattening out the planes of the box will present multiple views of the object - front, right side, left side, back, top, and bottom. An individual drawing orthographic views is forced to consider his concept in detail and true proportion as well as being able to mentally rotate the form and cut through its structure (McKim, 1972).

Measurement of Spatial Skills/Visualization

Isham (1997) developed a pencil-and-paper Visualization Assessment where architectural objects were shown as a series of orthographic and isometric drawings. This assessment if used by interior design programs may determine or strengthen a student's visualization skills. Periodic assessments would allow 
educators to compare results with previous ones to determine if the student is making progress in acquiring visualization skills required of professional designers. Evaluating entering design students will help establish a baseline for each individual as well as define the competency level for the entering class.

A Computerized Interactive Visualization Assessment employing animation was also developed. When a student answers a problem incorrectly, an animated image of the three-dimensional object rotates into the designated direction of view, immediately allowing an opportunity for the student to correct his mental image. These "visually neutral" animations permit the subjects to process and encode information using their unique design language (Isham, 1997).

FIDER accredited interior design programs participated in the assessment. To encompass the greatest diversity of skills, first semester freshmen and seniors were tested. Two hundred and fifty-two freshmen paper assessment packets were completed and returned. Results ranged from a low score of 18 percent to a high score of 98 percent, with an overall mean of 70.81 percent and a standard deviation of 17.56. Sixty-seven percent of the seniors, 149 , responded with a mean score of 84 percent, ranging from a low score of 20 percent to a high of 100 percent and a standard deviation of 14.56 . The wide range of scores within freshmen classes revealed the variety of skills and innate abilities of incoming freshmen. Unlike the freshmen, the seniors' scores were within a very narrow range, indicating common visualization skills seniors acquire approaching the end of their education (Isham, 1997). 
The paper assessment was used as a way of developing and validating the assessment with a large group of students. It could be easily sent to any location and did not require any specialized equipment. However, students who participated in the computerized assessment unanimously selected it as the most beneficial. The interactive component of the computerized version has the potential of increasing visualization skills (Isham, 1997).

Creativity

"Creativity may be defined, quite simply, as the ability to bring something new into existence" (Barron, 1969, p. 10). Research on bringing this new idea into existence has centered around four different approaches: the Person of the creator, the Process of creativity, the Environment in which creation comes about, and the Product created (Mooney, 1963).

The creative person approach focusing on individual personality traits favored by many personality psychologists goes back to the 1950s. Barron and Harrington (1981) listed a set of core characteristics of creative achievement:

High valuation of esthetic qualities in experience, broad interests, attraction to complexity, high energy, independence of judgment, autonomy, intuition, self-confidence, ability to resolve antinomies or to accommodate apparently opposite or conflicting traits in one's self-concept, and finally, a firm sense of self as 'creative' (p. 453).

The creative process approach examines how the mind processes ideas, problem solves and gains insight to form creative ideas. Koestler (1976) 
visualized the creative process as "signalled by the spontaneous flash of insight which shows a familiar situation or event in a new light, and elicits a new response..." (p.45). This process included "the displacement of attention to something not previously noted, which was irrelevant in the old and is relevant in the new context; the discovery of hidden analogies as a result of the former; $\ldots$ the uncovering of what has always been there" (p. 119). Newell, Shaw, and Simon (1962) stated that "creative activity appears simply to be a special class of problem-solving activity characterized by novelty, unconventionality, persistence, and difficulty in problem formulation" (p. 66).

The creative process has been described in five steps. The first step is a period of preparation where the individual becomes immersed, consciously or not, in the issues. The second phase is incubation where ideas churn around below the threshold of consciousness. The ideas call to each other and unexpected combinations may arise, as opposed to conscious thinking where we process information in a logical, linear way.

The third step in the creative process is insight where all the pieces of the puzzle fall into place. This "Eureka" phase may be interspersed with periods of incubation, evaluation, and elaboration. The fourth component is evaluation when an individual must determine if the insight is meaningful and worth pursuing. This period is one of self-criticism and soul searching.

The fifth and final step in the process is elaboration. This stage is the most difficult and time consuming. It is constantly interrupted by periods of incubation and fresh insights. Thus, the creative process is circuitous, traveling 
through loops, with new insights occurring throughout the journey, leading to more "Aha!" moments, and additional evaluations and elaborations (Csikszentmihalyi, 1996, p. 79).

Environmental studies focus on identifying patterns in the environment that foster creativity. Businesses, education, organizations and industries are invested in optimal physical surroundings which enhance creativity in the work place. An environmental approach also accounts for an explanation of creativity based on cultural or physical surroundings (Isaksen, 1987).

Research in the creative product approach examines original ideas. Original ideas imply newness or a new way of looking at an old idea. The concrete product becomes the article of interest and the researcher assesses its validity and quality. MacKinnon's study (1978) states the importance of studying the creative product:

In a very real sense...the study of creative products is the basis upon which all research on creativity rests and, until this foundation is more solidly built than it is at present, all creativity research will leave something to be desired (p. 187).

Jackson and Messick's study (1965) lists the aesthetic responses from observers of creative products as: surprise, satisfaction, stimulation, and savoring. While creative products are novel, they must also be appropriate. Stein (1974) emphasized novelty in his definition of creativity:

Various approaches agree that the resultant of the creative process is something novel. The novelty that is produced 
is of some significance, but novelty in some insignificant detail, while no doubt of worth, does not merit being called creative. The novel result is also useful, tenable, or satisfying....For the result to be called creative, it needs also to represent a "leap"... away from that which has existed...(p. 15).

The four approaches to researching creativity (the Person, the Process, the Environment, and the Product) all work to achieve the end result: the creative idea or product. The creative product is what will be assessed in this study.

\section{Measurement of Creativity}

Studies on creativity have yielded diverse measurements based on the four various approaches to the research. Of particular interest in this study is measurement of creativity based on the creative product.

Amabile (1983) defines the creative product in the following way:

A product or response is creative to the extent that appropriate observers independently agree it is creative. Appropriate observers are those familiar with the domain in which the product was created or the response articulated. Thus, creativity can be regarded as the quality of products or responses judged to be creative by appropriate observers, and it can also be regarded as the process by which something so judged is produced (p. 31). 
Amabile's consensual assessment technique specified a number of "appropriate observers," judges who have experience in the domain in question. These observers, selected only due to their familiarity with the domain should make assessments. Each judge makes assessments independently. The integrity of the assessment depends on agreement being achieved without any outside influences. Judges should be asked to make assessments on other dimensions, such as technical aspects of the work and aesthetic appeal. This would make it possible to determine if creativity is related to or independent of those dimensions. Products should be rated relative to one another rather than being rated on some absolute standard. Judges should view the products in a different random order and each judge should consider the various dimensions in a different random order.

Barnard (1992) adapted Amabile's consensual assessment technique for judging creativity in interior design. She developed the Consensual Assessment of Interior Design Creativity (CAIDC), based on Amabile's definitions of creativity and her componential framework of creativity and the creative process.

Barnard's study included twenty-eight subjects enrolled in a senior-level contract design class at a FIDER accredited university. Students were given a problem statement to design a free-standing, enclosed entry space for an exhibit entitled "Childhood Imagination" scheduled to open in the student center of the university during fall semester, 1992. The purpose of the entry space was to create an entrance into the secret, free, and imaginative world of the child. The 
final presentation included: floor plan, interior elevation or section, axonometric, and perspective vignette.

Expert judges evaluating the projects included interior design professionals -- both educators and practicing designers. Educator expertjudges were comprised of Corporate members of the Interior Design Educators Council (IDEC) who were faculty members at four-year interior design programs in Virginia and the District of Columbia. Designer expert-judges were professional members of the American Society of Interior Designers (ASID), practicing in the Roanoke, Richmond, or Arlington/District of Columbia geographic areas. Forty-four expert-judges participated, 13 educators and 31 designers.

Dimensions of judgment raters evaluated included: aesthetic appeal, appropriateness, artistic merit, complexity, craftsmanship, creativity, functionality, liking, novelty, originality, technical merit, and thematic expression. Eighteen projects were selected to be judged. Time to rate all eighteen was estimated to be two hours. Judges were scheduled for various times during the day and worked independently. They were instructed to use the rating sheets and assign ratings on each dimension of project merit and to consider all projects on one dimension before proceeding to the next dimension. Projects were considered in a random order and rated against each other, rather than some established standard.

Interjudge reliabilities exceeded the acceptable level of .70 on all 12 dimensions of judgment, with estimates ranging from .84 to .96 . Sub-categories 
also showed acceptable agreement, except for ratings by educators on appropriateness (.46) and functionality (.54). Interjudge reliability of creativity, the dimension of interest, was high for all groups. Mean ratings by educators (.85), designers (.93), and all judges (.95) were much higher than the criterion level of .70 .

Creativity ratings were found to correlate with a number of other dimensions of judgment, including novelty, originality, complexity, liking, and to a lesser extent, appropriateness and thematic expression. Associations between creativity and these dimensions for all judge groups provided support for convergent validity (Barnard, 1992).

\section{Link Between Spatial Skills and Creativity}

Visualizing a three-dimensional image and mentally rotating and transforming it provide a designer with multiple creative ideas for a design solution. This mental transformation helps achieve a delicate balance between reality and fantasy. The more ideas that a designer can brainstorm, the better the ability to realize the most creative solution. "The ability to concisely communicate a highly complex and creative design solution has at its creative core visualization skills (internal imaging) that allow designers to mentally create, manipulate and communicate solutions effectively" (Isham, p. 2, 1997). A correlation between complex spatial skills and creativity in interior design students would place emphasis on ways of teaching both methods of visualization and creativity-enhancing processes. 
Karlans, Schuerhoff, and Kaplan (1969) looked at the efficacy of certain factors as predictors of creative ability in architecture students. Subjects were 17 fourth-year undergraduate students in the Department of Architecture at Princeton University. Judges (raters) were two faculty members who had the most extensive contact with the fourth year students. Each faculty member rated each of the 17 subjects on seven different traits: (a) trait A--quantity, dependability, and speed of work; (b) trait B--skill in getting along with people; (c) trait C--creativity; (d) trait D--adaptiveness; (e) trait E--need to know; (f) trait F--dependence or independence; ego strength and open-mindedness; and (g) trait G--total contributions or productivity. The rater was required to rate all 17 subjects on one trait at a time on a 15-point scale.

Before filling out any of the rating scales the faculty members were asked to rank order the 17 subjects on creative ability. No definition of creativity was given to the raters for this task. They were told to use their own conception of creativity as their standard (trait H). The standard SAT Verbal and Math scores and class rank figures were used as the standard measure of overall college academic achievement. In addition, all grades received on independent design projects were averaged over two years and entered as an academic variable. The Wonderlic Personnel Test was used as the standard test of general intelligence in the study. It was expected that there would not be a significant relationship between creativity and intelligence scores for this group (average IQ $=128)$. This expectation was based on the conclusion that, in general, intelligence is related to creativity up to a certain IQ level (commonly located at 
around 120). The Remote Associates Test (RAT) was administered. This test consists of three stimulus words which the examinee is asked to relate to each other by means of a common association. Two tests measured spatial ability, the Cube Comparisons and the Surface Development Test. The Cube Comparisons test is designed to measure a "spatial orientation" factor. The Surface Development Test is designed to measure "visualization." A high correlation of scores on Cubes with rated creativity indicated that perhaps the spatial orientation factor it is designed to measure may be important to creativity in architecture (Karlans, et al., 1969).

The subjective nature of the faculty raters casts doubt on the creativity ratings of the architecture students. Although the faculty knew the students well and may have been able to accurately assess their creative abilities, a more objective rating by a consensual assessment technique may have produced different results.

Karlans and his colleagues suggested that creativity is related to spatial skills in architects. Although the same study has not been done with interior designers, the following discussion is an exploration of how spatial skills might be related to creativity for interior design work.

When a designer begins to design a room, they first have to visualize the space within the room. Secondly, they begin to visualize the architectural features of the space and the furnishings that will go into the room. In order to come up with alternate solutions for the space, the designer will transform the room and rotate the furnishings into various arrangements before coming to a 
final solution. If this cannot be accomplished, the designer cannot come up with creative design solutions for the problem. Strong spatial skills enable better visualization and the ability to visualize multiple solutions to design problems. The more creative a person is the more ideas one can generate. Thus, visualizing more novel ideas leads to greater creativity and vice versa. 


\section{CHAPTER III}

\section{METHODOLOGY}

$\underline{\text { Introduction }}$

The purpose of this study was to ascertain if there is a correlation between spatial skills and creativity in interior design students. From the review of literature it appears that there may be a relationship; therefore, the hypothesis of this study is:

$\mathrm{H}_{1}$ : There is a relationship between spatial skills and creativity in
interior design students.

Subjects

Subjects for this study were 33 sophomore interior design students enrolled in a Presentation Techniques class at a FIDER accredited university in southeastern United States during fall semester, 1999. Students entering this class can be assumed to have essentially the same background and training in interior design, all having completed two design fundamental courses covering two-dimensional and three-dimensional design, one drawing class emphasizing hand drafting and CAD, one design appreciation class, and having passed portfolio review. This factor controls for large individual differences in baseline performance skills. Students in the class were expected to participate in the project as a requirement for the class.

$\underline{\text { Visualization Assessment Instrument }}$

Isham's (1997) pencil-and-paper Visualization Assessment (Appendix H) was used to assess spatial skills. The test consists of two parts, each containing 
eighteen questions. Part One uses two-dimensional and three-dimensional drawings to identify the correct fifth view from four options. In Part Two, the student is given a three-dimensional view and asked to identify the incorrect twodimensional view from three options.

The pencil-and-paper Visualization Assessment was used by Isham to develop, validate assessment problems and establish a benchmark for evaluation of the computerized version. Errors and omissions reported by Isham (1997) include the following:

Question \#3: The arrowhead asking for the designated direction of view (solid black one) was in the wrong location. However, sufficient information, either in the provided two-dimensional views or the available options, was given that offset the wrongful placement of the arrow. The resulting score for that question was consistent with the rest of the asssessment.

Question \#15: The mistaken placement of the designated direction of view arrowhead resulted in the lowest percentage of correct responses of the entire assessment.

Question \#31: Lines shown as a solid (object) lines should have been dashed (hidden) lines.

Questions \#19, 20, and 33: The omission of hidden lines on one or more of the views. Question \#19 presents an interesting problem where freshmen, due to a lack of knowledge, did not recognize 
that both Option A - Plan and Option C - Right Elevation contained drawing mistakes. They selected the most obvious incorrect answer, the plan, as the right answer which was correct. Seniors, possibly recognized both of these errors, resulting in one of the two questions that the freshmen out scored the seniors. Comparing questions \#19,20, and 33 with the rest of the assessment showed that these simple types of errors had dramatic affects on the percentage of correct responses.

Question \#34: The front and right elevations options were reversed, not following standard drawing conventions. Switching the elevations did not affect the freshmen's scores, while the seniors possibly recognized that the elevations were reversed and that one of the elevations contained an error. This combination resulted in the second question in which the freshmen scored higher than the seniors (Isham, pg. 5, 1997).

Due to errors and omissions reported by Isham in the Visualization Assessment, problem numbers $3,15,19,20,31,33$, and 34 were eliminated in the Adjusted Visualization Assessment scores for this study. Creativity Assessment Instrument

The creativity assessment was based on Barnard's Consensual Assessment of Interior Design Creativity (CAIDC) (1992). Judges evaluating the projects were interior design educators and interior design graduate students having previous work experience that were currently enrolled at a FIDER 
accredited interior design program of a university in southeastern United States. Eleven raters participated. Judges rated each project against the other projects rather than some established standard.

The rating criteria used by the expert-judges included Appropriateness, Creativity and Novelty. The three criteria were taken from Barnard's (1992) instrument, the Consensual Assessment of Interior Design Creativity (CAIDC), which was adapted from Amabile's Consensual Technique for Creativity Assessment (1983). Each dimension was accompanied by a description (e.g., "Creativity: The degree to which the design is creative, using your own subjective definition of creativity.") Dimensions of Judgment for Interior Design Projects with descriptions is listed in Appendix C.

A separate rating sheet (Appendix D) was given for each of the three dimensions. Each sheet was labeled with the dimension, its definition, and a nine-point rating scale from $1=$ VERY LOW to $9=$ VERY HIGH. $\underline{\text { Judges }}$

Expert-judges for the study included interior design professionals educators and graduate students in interior design who had previous work experience in the field. Barnard's (1992) study found a high degree of reliability between interior design educators and professionals in the field in rating interior design projects on creativity; therefore, creativity ratings for this study were done by both educators and graduate students having previous professional experience. 
A letter explaining the study and requesting participation (Appendix E) was sent to the eleven judges. The letter avoided directly referring to creativity as the construct under investigation. Each letter was followed by a verbal request to determine willingness to take part in the judging and schedule an appointment. All judges asked agreed to participate and scheduled an appointment for one of the two days of the experiment.

All eleven judges, eight educators and three interior design graduate students, kept the scheduled appointment.

\section{Procedures}

Students in the Presentation Techniques class completed a demographic questionnaire (including classification in school, age, and gender) and the penciland-paper version of the Visualization Assessment. The Visualization Assessment took approximately 30 minutes to complete.

A project created for the Presentation Techniques class was used for the creativity assessment. It was theorized that the open-ended nature of the project assignment would allow a great deal of opportunity for students to develop highly creative design solutions. The project required the students individually to brainstorm ideas for an entertainment space designed for 20 college age individuals where physical activity is a main component. They were asked to present their ideas in a schematic method, using marker-sketching techniques acquired in previous projects and using conceptual thumbnails and marker sketches. Other visual materials to be incorporated included plans, elevations, diagrams and details, as well as one larger perspective sketch. People and 
materials had to be represented throughout the space. The project could be as abstract or realistic as the student wanted but it had to be completed on a single

sheet of paper mounted to a board. Titles were placed on the front of the board, but names were only placed on the back of the board with a signature supporting the honor system (see Appendix $\mathrm{J}$ for representative projects).

\section{Project Creation Session}

The project was announced in the course syllabus as a scheduled activity for the class. The project was completed in the regular classroom over a threeclass period in the fall semester. Students used the drafting tables that are normally provided in the classroom. Projects were graded by the instructor as well as being used in the study. Each student provided his or her own materials. A copy of the Project Statement detailing the requirements of the project (Apppendix B) was given to the students as part of the course syllabus.

Students were told by the instructor to produce a one-sheet presentation of a schematic design for an entertainment space incorporating the requirements from the project statement. Specific references to "creativity" were avoided. Students were instructed to work alone and to sign the Honor Code Statement assuring that their work was done on an individual basis.

After project grades were assigned, the instructor discussed details of the present study during a regular class meeting. 


\section{Project Judging Sessions}

Two separate one-day project judging sessions were held on a campus of a FIDER accredited university in southwest Virginia. Expert-judges were scheduled for appointments at staggered times during the single-day sessions. Physical Setting. The judging session was held in the Lighting Lab which is set up with large drafting tables in a well-lit environment. Drafting tables were arranged to provide easy access to each project and to facilitate ease of viewing. Projects were placed directly on drafting tables and on a wide elevated window sill transversing one side of the room. A table with a chair was provided at the front of the room for judges to read the instructions for the rating session. Materials. A clipboard was given to each judge upon arrival with instructions for the project rating session. Included were the Instructions for the Project Judging Session (Appendix F), the Project Statement (Appendix B), the Dimensions of Judgment for Interior Design Projects (Appendix C), individual Rating Sheets for each dimension (Appendix D) randomly prearranged, and a demographics sheet (Appendix G).

Procedures. The researcher administered each of the two project judging sessions. Upon arrival, judges were presented with the prepared clipboards and after reviewing these, any questions were answered by the researcher.

Judges were asked to assign ratings on one dimension for all projects before continuing to the next dimension. They were instructed to consider projects in any random order of their choice and to rate projects relative to one another rather than to some established standard for work in the field. Lastly, 
they were asked to make independent assessments with no discussion or collaboration if more than one judge were present at any given time.

After completion of the rating session, judges were instructed to make sure that each of the three rating sheets were complete and to then fill out a demographic information sheet (Appendix G). The demographic information sheet detailed their background and experience including principal employment, interior design focus and expertise, degrees held, academic discipline describing their education and training, number of years in the profession, gender, and any difficulties encountered during the judging session.

When both judging sessions were completed, judges received a letter (Appendix E) thanking them for their participation and explaining the purpose of the study.

\section{Data Analysis}

A Visualization Assessment score for each of the participants was determined by summing the number of correct answers and calculating a percentage of the total number correct, and was entered into the computer. An Adjusted Visualization Assessment score was calculated in the same manner, but eliminating questions that presented problems in the initial tests of the instrument (Questions 3, 15, 19, 20, 21, 31, 33, and 34). Ratings for each of the 33 projects on each of the three dimensions by each of the 11 expert-judges were coded and transferred to the computer. Mean scores of each of the three Dimensions of Judgement were calculated. A Pearson product-moment 
correlation was examined to determine if spatial skills explain or account for variance in creativity. Demographic data from each judge's personal information sheet were also recorded in the computer file.

The SPSS (Statistical Package for the Social Sciences) 7.5 for Windows was used to obtain descriptive analyses of the demographic data. Frequencies and percentages regarding various aspects of judges' background, training, and experience were generated.

To investigate the degree to which interior design professionals agree on ratings of interior design project merit, a process first described by Hoyt (1941) and later by Winer (1971) was used to estimate interjudge reliability. 
CHAPTER IV

RESULTS AND DISCUSSION

The purpose of this research was to determine if there is a correlation between spatial skills and creativity in interior design students. Using Isham's (1997) Visualization Assessment and an interior design class project, a set of participants was examined to determine if a correlation exists between their spatial skills (tested by the Visualization Assessment) and their creativity levels (measured on the design projects). This chapter outlines the results obtained from these measures and is organized into the following sections: Description of Participants; Statistical Findings; and Discussion of Findings.

\section{Description of Participants}

Participants for the study were subjects who completed a Visualization Assessment and created an interior design project, and the judges who assessed the merit of the projects. Characteristics of these two groups of participants are described in the following section.

\section{$\underline{\text { Subjects }}$}

Subjects were 33 interior design students at a large land-grant university in southwest Virginia. All students were in the second year of the interior design program. The age range of the subjects varied from 18 to 25 years old, with the majority (76\%) falling into the 19 and 20 year old range. Females represented the majority of subjects with $76 \%$ females and $24 \%$ males. The students had essentially the same classroom background and training in the program and had also passed portfolio review. Design courses taught in the first year of the 
program included: design lecture (3 semester credits), two-dimensional and three-dimensional design ( 6 semester credits), and design drawing (3 semester credits) combining both two-dimensional CAD and manual drafting. Judges

Judges were 11 professional experts in the field of interior design, including eight educators and three graduate students having previous or current professional work experience in the field of interior design. The majority of the judges were female (9 judges), with male judges comprising only $18 \%$ of the total sample (2 judges). There was a wide range in levels of experience in interior design from those having less than 5 years to one judge having 31 or more years of experience.

Based upon self-classification of their primary focus and expertise, almost two-thirds of the judges (63.6\%) identified themselves as specialists in contract design. Residential design practice accounted for $9 \%$ of the judges and $18 \%$ accounted for those whose work was an equal combination of residential and contract design.

The educational backgrounds of the judges varied from those having a bachelor's degree only and currently working on a master's degree to those having a doctorate. The majority of the judges (73\%) had a master's degree or were currently completing their master's degree. Three judges (27\%) had completed doctorate degrees.

When asked to identify the academic discipline in which their training in interior design had been administered, the majority (72.7\%) classified their 
program as interior design. One judge (9\%) classified his program as split between art and interior design and one judge (9\%) was split between architecture and interior design.

\section{Statistical Findings}

$\underline{\text { Visualization Scores }}$

Scores on the Visualization Assessment ranged from a low score of 53 to a high score of 92 . The mean was 75 with $18.2 \%$ of the subjects receiving this score. Scores on the Adjusted Visualization Assessment ranged from a low score of 55 to a high score of 97 . The mean for the adjusted instrument was 80.5 .

\section{Creativity Ratings}

Creativity ratings ranged from a low score of one to a high score of nine. The majority of ratings were in the three to four range accounting for $40 \%$ of the total ratings.

Interjudge Reliability

Interjudge reliabilities (Winer, 1971) for mean scale ratings for the group of judges are presented in Table 1. Of primary interest for this study was the interjudge reliability of the Creativity dimension, which was high (.866) and far above the criterion level of .70. Reliabilities exceeded the acceptable level of .70 on all three dimensions of judgement, with estimates ranging from .729 to .866 . 


\section{Table 1}

Interjudge Reliabilities for Mean Scale Ratings on Dimensions of Judgment

Dimension of Judgment Interjudge Reliability

Appropriateness $\quad .729$

Creativity $\quad .866$

Novelty $\quad .803$ 


\section{$\underline{\text { Intercorrelations among Dimensions }}$}

Pearson product-moment correlations among the three Dimensions of Judgment indicated a high degree of association between variables (see Appendix H). Appropriateness and Novelty were both significantly correlated $(\underline{p}<.001)$ with the Creativity dimension (see Figure 1 and 2$)$.

Correlation between Visualization and Creativity

Pearson product-moment correlation was used to determine if there was a significant correlation between visualization and creativity. Tests were run on the Visualization Assessment score and the Adjusted Visualization Assessment score. No significant correlation was found between visualization and creativity $(\underline{p}=.343)$. Also, no significant correlation was found between the adjusted visualization score and creativity $(\underline{p}=.341)$. Kendall's tau test and Spearman's rho test were also run indicating no significant finding. Results are presented in Table 2 and Table 3 (also see Figure 3 and 4). Consequently, the hypothesis

$H_{1}$ : There is a relationship between spatial skills and creativity in interior design students

is rejected. 


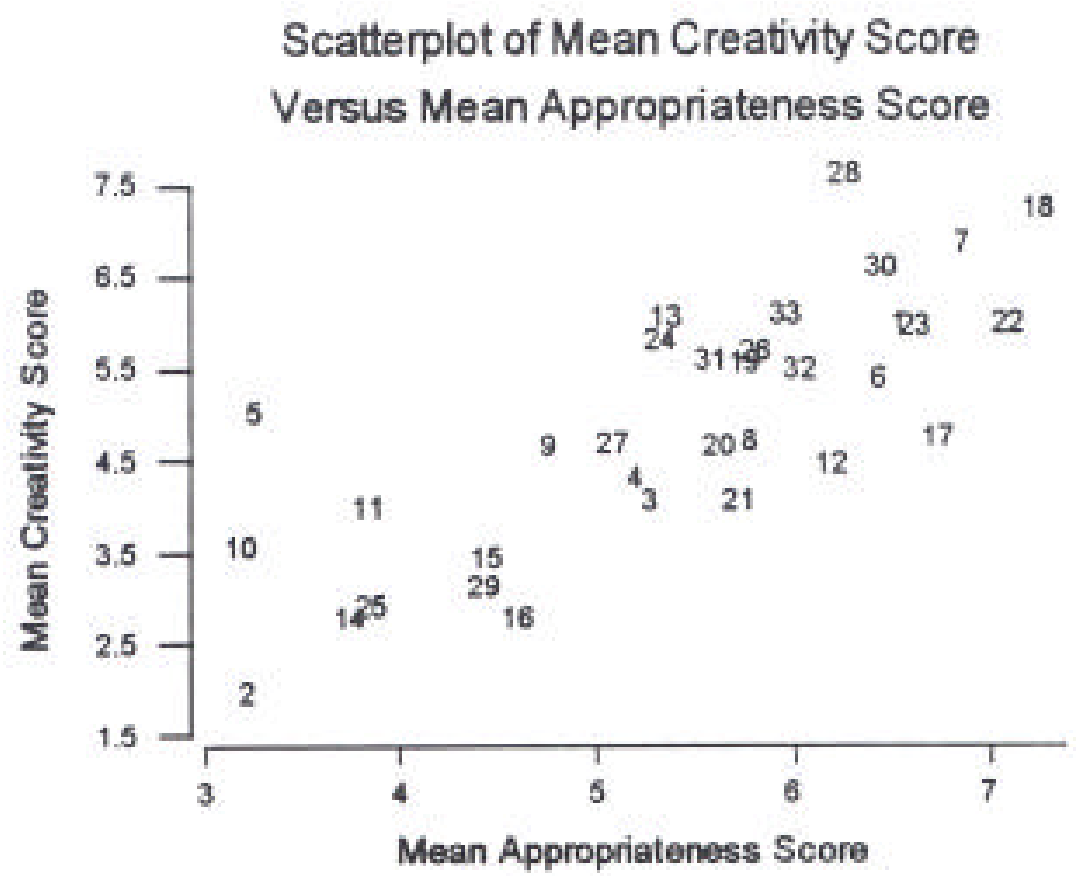

Figure 1: Mean Creativity Score versus Mean Appropriateness Score 


\section{Scatterplot of Mean Creativity Score}

Versus Mean Novelty Score

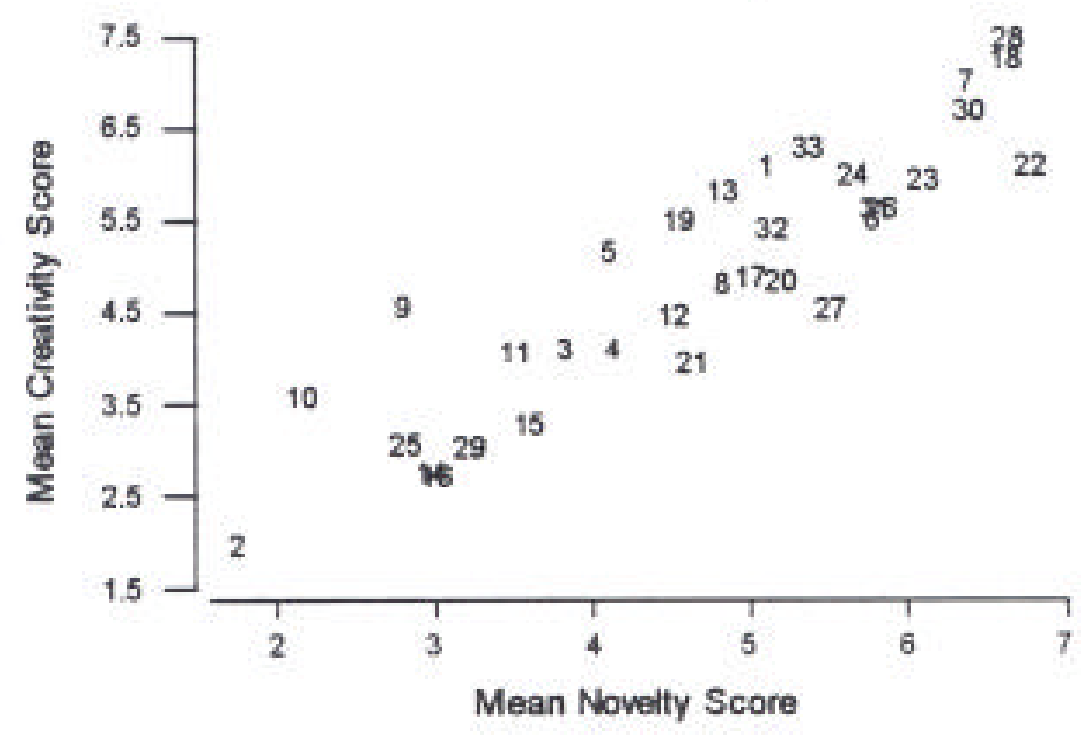

Figure 2: Mean Creativity Score versus Mean Novelty Score 


\section{Table 2}

Correlations of Visualization Scores with Creativity Scores

\begin{tabular}{llr}
\hline Visualization & Pearson Correlation & .171 \\
& Sig. (2-tailed) & .343 \\
& $\mathrm{~N}$ & 33 \\
\hline & & \\
\hline Visualization & Kendall's tau & .130 \\
& Sig. (2-tailed) & .309 \\
& $\mathrm{~N}$ & 33 \\
\hline Visualization & & .204 \\
\hline & Spearman's rho & .255 \\
& Sig. (2-tailed) & 33 \\
\hline
\end{tabular}




\section{Table 3}

Correlations of Adjusted Visualization Scores with Creativity Scores

\begin{tabular}{llc}
\hline Adjusted Visualization & Pearson Correlation & .171 \\
& Sig. (2-tailed) & .341 \\
& $\mathrm{~N}$ & 33 \\
\hline & & \\
\hline Adjusted Visualization & Kendall's tau & .140 \\
& Sig. (2-tailed) & .274 \\
& $\mathrm{~N}$ & 33 \\
\hline & & .193 \\
\hline Adjusted Visualization & Spearman's rho & .282 \\
& Sig. (2-tailed) & 33 \\
\hline & $\mathrm{N}$ & \\
\hline
\end{tabular}




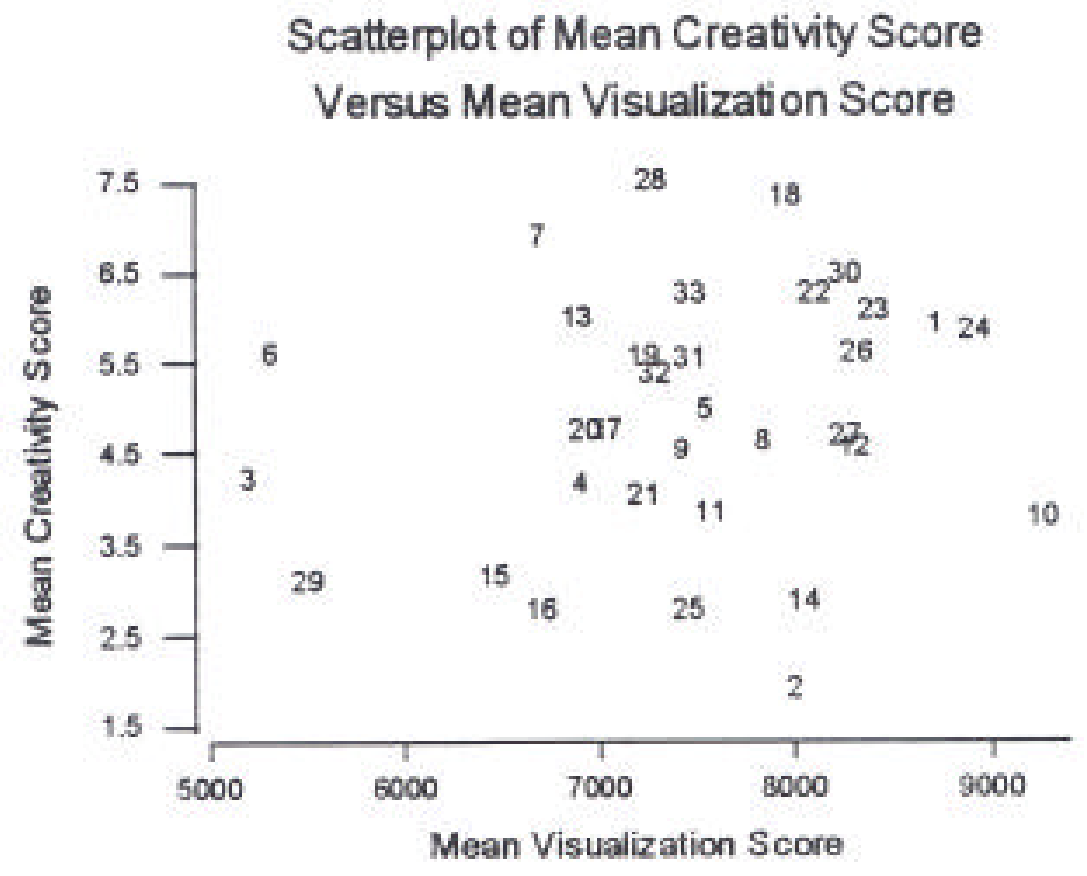

Figure 3: Mean Creativity Score versus Mean Visualization Score 


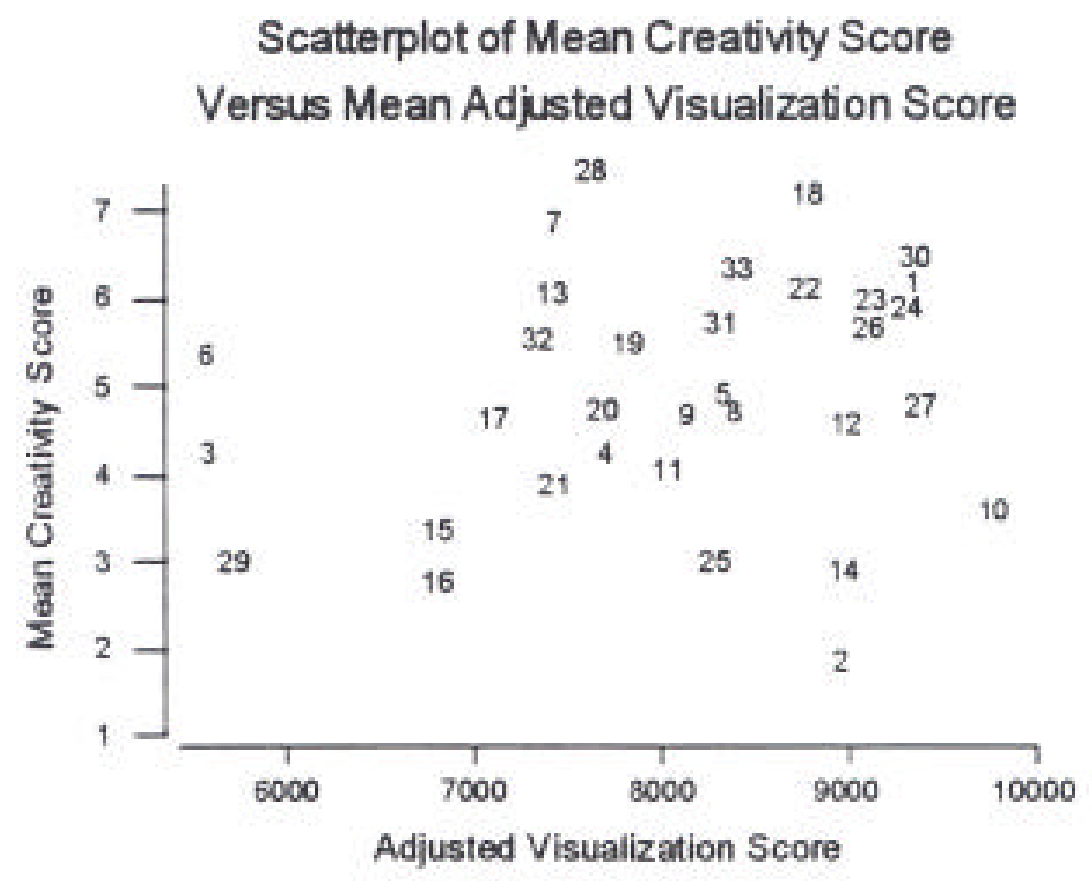

Figure 4: Mean Creativity Score versus Mean Adjusted Visualization Score 


\section{Discussion of Findings}

Results of this study provided no evidence in support of a correlation between visualization and creativity. The results indicated either that there is no correlation between creativity and visualization or that the measures might not measure what they were intended to measure, i.e. they lacked validity. The creativity measure by Barnard (1992) is validated by her study and Brandon's (1994), but perhaps the project was not a good choice for this study due to the open-ended requirements of the project. Students were instructed to design an entertainment space where "...Everything else is up to you. This is a brainstorm and your imagination is the limit... This project can be as abstract or as realistic as you want..." (Appendix J).

The question arises in the end were the judges rating projects with better presentations as being more creative. The definition of Creativity on the dimensions of judgment sheet (Appendix C) defined creativity as "the degree to which the design is creative, using your own subjective definition of creativity". A space less familiar to the students with more design parameters might have been better for this study and resulted in different creativity ratings.

With the small sample size of 33 students, the Visualization Assessment score might need be more discriminating. Errors and omissions reported by Isham in the Visualization Assessment included numbers 3, 15, 19, 20, 31, 33, and 34. These problem questions were eliminated in the Adjusted Visualization Assessment scores for this study. 
Ratings by interior design professionals did show agreement on creativity levels. Eleven judges were used in this study fulfilling Amabile's requirement of 10 or more judges needed to evaluate projects in the artistic domain. Although judges showed significant agreement on creativity levels, these creativity levels failed to show a correlation with the visualization scores. Thus, for the present study, support for a correlation between visualization and creativity was not found. Based on these results, it is unclear whether there is a link between spatial skills and creativity in interior design students. 


\section{CHAPTER V}

\section{SUMMARY AND CONCLUSIONS}

The purpose of this chapter is to summarize the study and its findings, and to suggest its potential contribution to the field. The chapter will summarize the focus of the study, the methodology used, and the results of the study. The chapter ends with discussion and recommendations.

\section{Summary}

Creativity and visualization are essential competencies in interior design, both necessary for success in the professional realm. Although correlation has been found between spatial skills and creativity in architecture students (Karlan, et al., 1969), no such correlation has been shown in interior design students.

The purpose of this study was to determine if there is a correlation between spatial skills and creativity in interior design students. It was theorized that a correlation between spatial skills and creativity would demonstrate the need to emphasize these skills in interior design programs and lead to further research into alternative methods of teaching these skills. It was also theorized that emphasis on one of these skills would positively influence the other and vise versa.

Participants were subjects who completed a Visualization Assessment and created 33 projects used in the study and the 11 expert-judges who rated the projects. The sample of subjects was comprised of interior design students at a FIDER-accredited institution in southwest Virginia. Eleven judges consisted of interior design educators and interior design graduate students having previous 
or current experience in interior design. The educators taught in interior design programs in southwest Virginia and the graduate students attended a FIDERaccredited university in southwest Virginia.

Visualization Assessments were graded by the researcher and given a percentage score based on the number of correct answers. Projects were assessed by subjective ratings by the judges on three rating criteria. These ratings were collected during on-site judging sessions.

A process described by Winer (1971), and based on analysis of variance (ANOVA) results estimated interjudge reliability of the ratings. Interjudge reliabilities exceeded the established criterion level (.70 or greater) on all three dimensions included in the rating criteria, with coefficients ranging from .729 to .866. Of primary interest was the interjudge reliability of the Creativity variable (.866), which indicated a high level of agreement on creativity judgments among these interior design professional experts.

Correlations among dimensions was used to examine the extent that the dimensions of Appropriateness and Novelty correlate with Creativity. Appropriateness and Novelty were found to be highly correlated with Creativity. Correlations among the Creativity dimension and the Visualization Assessment were used to determine if a significant relationship exists and if so, the extent to which visualization skills explain or account for variance in creativity or vise versa. No significant relationship was found, consequently, the hypothesis 
$\mathrm{H}_{1}$ : There is a relationship between spatial skills and creativity in interior design students

is rejected.

\section{$\underline{\text { Recommendations/Discussion }}$}

This section contains discussion and recommendations for further research on visualization and creativity.

Further research is needed to determine if there is a link between spatial skills and creativity in interior design students. Specifically, a revision of the project assignment to include more controlled requirements is recommended. The projects utilized in this study were a class assignment where the students were encouraged to "be limited only by their imaginations" (see Appendix J). It would be useful to repeat the study with another project assignment, a more abstract project with more design criteria required, thereby allowing for more discrimination on the judges' rating scales.

Corrections to the Visualization Assessment or eliminating the problem questions from the instrument may result in a different outcome. It is recommended that should the study be repeated, problem questions be resolved when using the paper-and-pencil version of the instrument.

Another strategy for improving discrimination would be to revise the terminology and definitions of the rating scales. Two judges expressed concern regarding the definition of Novelty, one regarding Appropriateness and one regarding Creativity. 
Fatigue was listed as a problem on one of the judge's demographic data sheets, and two judges verbally expressed their fatigue with rating three dimensions of judgment with this number of projects. Since the three measures were highly correlated, using only the one measure of Creativity would have allowed the judges to complete the process more quickly thus lessening fatigue.

Further research might follow a set of participants from entering freshmen status throughout their four years of study in order to determine if visualization and creativity increase throughout the four years of design school. A study using upper class students could show differing results since creativity and visualization may increase with years of study.

Further research might also utilize Isham's (1997) computer-generated Visualization Assessment to compare it with the paper-and-pencil version and to determine if the computer-generated assessment correlates with creativity for interior design students.

\section{Afterword}

The nature of the interior design profession is such that spatial skills and creativity are major factors in working and attaining success in the field. Although this study has not shown a significant correlation between spatial skills and creativity in interior design students, it is theorized that this link may be found in future studies. Interior design is an interdisciplinary profession with technical, creative, and aesthetic aspects intertwined. As the profession continues to evolve, research will help to further define our profession, what we do, and the ways we go about it. 


\section{REFERENCES CITED}

Amabile, T. M. (1983). The social psychology of creativity. New York: Springer-Verlag.

Arnheim, R. (1969). Visual thinking. Berkeley: University of California Press.

Ballast, D. K. (1992). Interior design reference manual: A guide to the NCIDQ exam. Belmont, CA: Professional Publications, Inc.

Barnard, S. S. (1992). Interior design creativity: The development and testing of a methodology for the consensual assessment of projects. Unpublished doctoral dissertation, Virginia Polytechnic Institute and State University, Blacksburg, Virginia.

Barron, F. (1969). Creative person and creative process. New York: Holt, Rinehart and Winston, Inc.

Barron, F. \& Harrington, D. M. (1981). Creativity, intelligence and personality. Annual Review of Psychology, 32, $439-476$.

Brandon, L. (1994). Computers in the design process: Comparing creativity ratings of interior design solutions using pencil-based and computerbased design methods in schematic development. Unpublished doctoral dissertation, Virginia Polytechnic Institute and State University, Blacksburg, Virginia.

Csikszentmihalyi, M. (1996). Creativity: Flow and the psychology of discovery and invention. New York: Harper Collins Publishers, Inc. 
Edward, B. (1989). Drawing on the right side of the brain. New York: Penguin Putnam, Inc.

Foundation for Interior Design Education Research. (1993). FIDER standards and guidelines for the accreditation of first professional degree level programs in interior design. New York: Author.

Hoyt, C. (1941). Test reliability obtained by analysis of variance.

Psychometrika, $\underline{6}, 153-160$.

Isaksen, S. G. (Ed.). (1987). Frontiers of creativity research: Beyond the basics. Buffalo, NY: Bearly Limited.

Isham, D. (1997, Fall). Developing a computerized interactive visualization assessment. JCAEDE [On-line serial] 1 (3), 1-15. Available http://borg.lib.vt.edu/ejournals/JCAEDE/v3n1/

Jasckson, P. W. \& Messick, S. (1965). The person, the product and the response: Conceptual problems in the assessment of creativity. Personality, 33, $309-329$.

Karlans, M. Schuerhoff, C., and Kaplan, M. (1969). Some factors related to architectural creativity in graduating architectural students. Journal of General Psychology, 81, $203-215$.

Koestler, A. (1976). The act of creation. London: Hutchinson and Company Ltd.

MacKinnon, D. W. (1978). In search of human effectiveness: Identifying and developing creativity. Buffalo, NY: Bearly Limited.

McKim, R. H. (1972). Experiences in visual thinking. Monterey, CA: Brooks/Cole Publishing Company. 
Mooney, R. L. (1963). A conceptual model for integrating four approaches to the identification of creative talent. In C. W. Taylor \& F. Barron (Eds.),

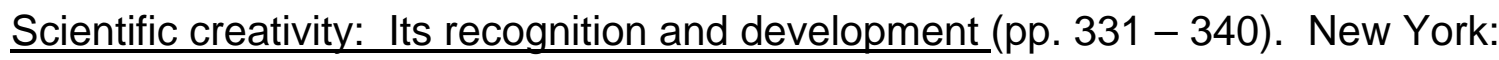
John Wiley.

Myers, C. (1982). Entry level competencies needed by interior designers. Journal of Interior Design Education and Research, 8 (1).

Newell, A., Shaw, J. \& Simon, H. (1962). The processes of creative

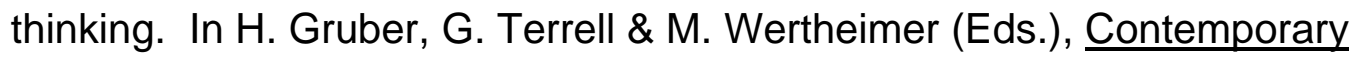
approaches to creative thinking. New York: Atherton Press.

Schank, R. C. (1988). The creative attitude: Learning to ask and answer the right questions. New York: Macmillan Publishing Company.

Stein, M. I. (1974). Stimulating creativity, (Vol. 1). New York: Academic Press.

West, T. G. (1997). In the mind's eye. Amherst, NY: Prometheus Books.

Winer, B. (1971). Statistical principles in experimental design $\left(2^{\text {nd }}\right.$ ed. $)$. New York: McGraw-Hill.

Yepsen, R. B., Jr. (1987). How to boost your brain power. Emmaus, PA: Rodale Press.

Zavotka, S. L. (1986). Analysis of three dimensional computer graphics animation to teach spatial skills to interior design students. Journal of Interior Design Education and Research, 12, (1), $45-52$ 


\section{APPENDIX A}

Permission to use Isham's Instrument 

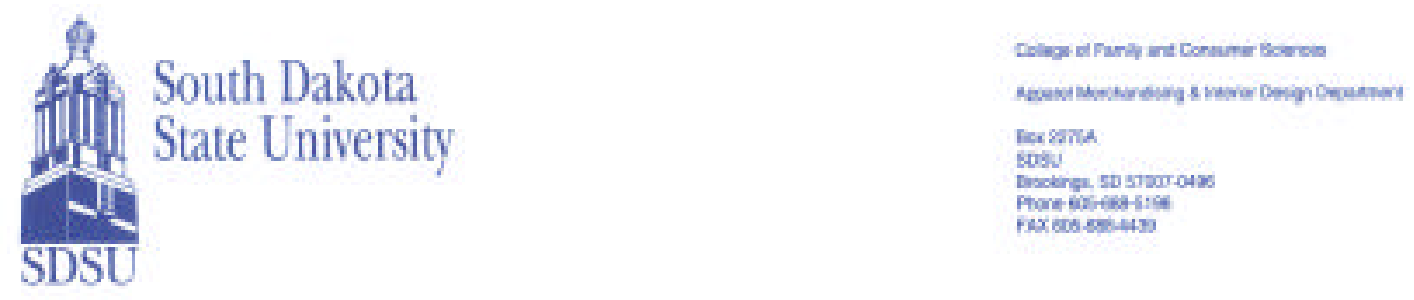

April 7, 1999

April Allen

405 Progress St., Apt. 4

Blacksburg, VA 24060

Dear April,

I grant you permission to use my visualization skills assessment. I would like to see a finished copy of your thesis so I can check to see how my test is functioning.

Sincerely,

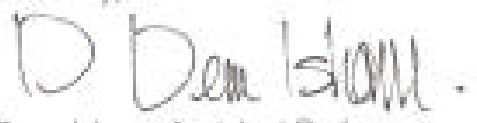

Dean Isham, Assistant Protessor

South Dikota State Universty

Brcokings, SO 57007 
APPENDIX B

Project Statement 


\section{PROJECT STATEMENT}

\section{Project 3: Conceptual Sketching}

Objective: The last project in a series of three where you are exploring methods of schematic presentations. This project will show an advanced understanding of schematic presentation methods. You will present your design with an intensive integration of graphic and verbal material.

Requirements: On one 20x30 board illustrate concepts for an entertainment space designed only for a college age group of 20 individuals where physical activity is a main component. Everything else is up to you. This is a brainstorm and your imagination is the limit. Present your ideas in a schematic method, using marker-sketching techniques acquired in previous projects. Use conceptual thumbnails and marker sketches. Incorporate other visual material as well, such as plans, elevations, diagrams, details etc. In addition, one larger perspective sketch is required. People and materials must be represented throughout your space. This project can be as abstract or as realistic as you want but it must be completed on a single sheet of paper mounted to board and effectively portray your concept. Put title on front of board but name must be on back with the below signature sheet attached.

Grading Criteria: Organization and composition; media technique; tonal value; drawing style; color and professional presentation.

\section{Honor System Signature Document}

In support of the Honor System, "Any student who gives or receives information concerning a test, quiz, examination, or project, or who violates the professor's specific instructions for the particular work, or who falsifies, verbally, or in writing, any circumstances relevant to his/her academic work, shall be in violation of the Honor Code."

I hereby state that I have neither received help from others nor given help to others during the time allotted for project 3.

Name:

(Signature)

Date:

(Printed) 


\section{APPENDIX C}

Dimensions of Judgment for Interior Design Projects 
Dimensions of Judgment for Interior Design Projects

Dimension

Appropriateness

Creativity

Novelty
Descriptive Definition

The degree to which the design is an appropriate solution to the problem.

The degree to which the design is creative using your own subjective definition of creativity.

The degree to which the use of materials and/or design elements is novel. 


\section{APPENDIX D}

Rating Sheets 
Judge No.

APPROPRIATENESS: The degree to which the design is an appropriate solution to the problem.

Please rate ( _ _ ) each project from VERY LOW to VERY HIGH on the aspect described above.

Rate projects RELATIVE TO ONE ANOTHER, not according to some absolute standard for excellence. Consider projects in ANY RANDOM ORDER, and indicate the number of the project being rated $[1-36]$ in the bracket provided on the left.

VERY LOW

VERY HIGH

\begin{tabular}{|c|c|c|c|c|c|c|c|c|c|c|}
\hline \multicolumn{10}{|c|}{$\begin{array}{l}\text { Project } \\
\text { Number }\end{array}$} & \\
\hline[ & ] & (1)__ & (2) & (3) & (4) & (5) & (6) & (7) & $(8)$ & (9) \\
\hline[ & ] & (1) & (2) & (3) & (4) & (5) & (6) & (7) & (8) & (9) \\
\hline [ & ] & (1) & (2) & (3) & (4) & (5) & (6) & (7) & (8) & (9) \\
\hline[ & ] & (1) & (2) & (3) & (4) & (5) & (6) & (7) & (8) & (9) \\
\hline[ & ] & (1) & (2) & (3) & (4) & (5) & (6) & (7) & $(8)_{-}$ & (9) \\
\hline [ & ] & (1) & (2) & (3) & (4) & (5) & (6) & (7) & (8) & (9) \\
\hline [ & ] & (1) & (2) & (3) & (4) & (5) & (6) & (7) & $(8)_{-}$ & (9) \\
\hline [ & ] & (1) & (2) & (3) & (4) & (5) & (6) & (7) & $(8)_{-}$ & (9) \\
\hline[ & ] & (1) & (2) & (3) & (4) & (5) & (6) & (7) & (8) & (9) \\
\hline [ & ] & (1) & (2) & (3) & (4) & (5) & (6) & (7) & $(8)_{-}$ & (9) \\
\hline [ & ] & (1) & (2) & (3) & (4) & (5) & (6) & (7) & $(8)_{-}$ & (9) \\
\hline [ & ] & (1) & (2) & (3) & (4) & (5) & (6) & (7) & $(8)_{-}$ & (9) \\
\hline [ & ] & (1) & $(2)_{-}$ & (3) & (4) & (5) & (6) & (7) & $(8)_{-}$ & (9) \\
\hline [ & ] & (1) & $(2)_{-}$ & (3) & (4) & (5) & (6) & (7) & $(8)_{-}$ & (9) \\
\hline [ & ] & (1) & $(2)_{-}$ & (3) & (4) & (5) & (6) & (7) & (8) & (9) \\
\hline [ & ] & (1) & $(2)_{-}$ & (3) & (4) & (5) & (6) & (7) & $(8)_{-}$ & (9) \\
\hline [ & ] & (1) & (2) & (3) & (4) & (5) & (6) & (7) & (8) & (9) \\
\hline [ & ] & (1) & (2) & (3) & (4) & (5) & (6) & (7) & (8) & (9)_ \\
\hline
\end{tabular}


APPROPRIATENESS: The degree to which the design is an appropriate (continued) solution to the problem.

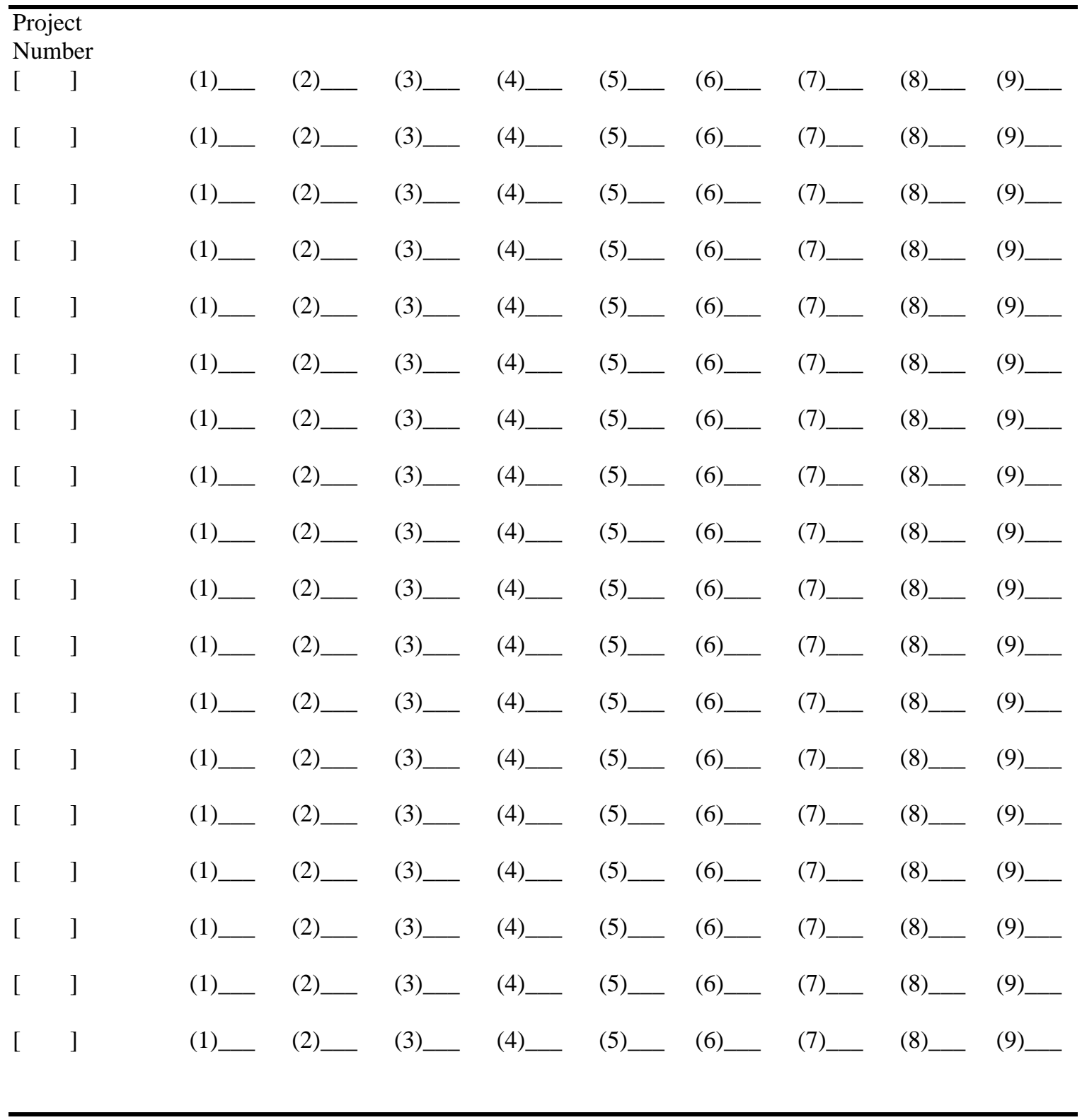

The following list of consecutive numbers ( $1-36$ ) has been provided for your convenience in crossing off projects during the rating process, if desired:

$$
\begin{array}{lllllllllllllllllll}
1 & 2 & 3 & 4 & 5 & 6 & 7 & 8 & 9 & 10 & 11 & 12 & 13 & 14 & 15 & 16 & 17 & 18 & 19 \\
20 & 21 & 22 & 23 & 24 & 25 & 26 & 27 & 28 & 29 & 30 & 31 & 32 & 33 & 34 & 35 & 36
\end{array}
$$


Judge No.

CREATIVITY: $\quad$ The degree to which the design is creative, using your own subjective definition of creativity.

Please rate ( _ _ ) each project from VERY LOW to VERY HIGH on the aspect described above. Rate projects RELATIVE TO ONE ANOTHER, not according to some absolute standard for excellence. Consider projects in ANY RANDOM ORDER, and indicate the number of the project being rated $[1-36]$ in the bracket provided on the left.

VERY LOW

VERY HIGH

\begin{tabular}{|c|c|c|c|c|c|c|c|c|c|c|}
\hline \multicolumn{11}{|c|}{$\begin{array}{l}\text { Project } \\
\text { Number }\end{array}$} \\
\hline[ & ] & (1) & (2) & (3) & (4) & $(5)_{-}$ & (6) & (7) & (8) & $(9)_{-}$ \\
\hline[ & ] & (1) & (2) & (3) & (4) & $(5)_{-}$ & (6) & (7) & (8) & $(9)_{-}$ \\
\hline [ & ] & (1) & (2) & (3) & (4) & $(5)_{-}$ & (6) & (7) & (8) & $(9)_{-}$ \\
\hline[ & ] & (1) & (2) & (3) & (4) & (5) & (6) & (7) & (8) & (9) \\
\hline [ & ] & (1) & (2) & (3) & (4) & $(5)_{-}$ & (6) & (7) & (8) & $(9)_{-}$ \\
\hline[ & ] & (1) & (2) & (3) & (4) & (5) & (6) & (7) & (8) & $(9)_{-}$ \\
\hline[ & ] & (1) & (2) & (3) & (4) & (5) & $(6)_{-}$ & (7) & (8) & (9) \\
\hline [ & ] & (1) & (2) & (3) & (4) & $(5)_{-}$ & $(6)_{-}$ & (7) & (8) & (9) \\
\hline[ & ] & (1) & (2) & (3) & (4) & (5) & (6) & (7) & (8) & (9) \\
\hline[ & ] & (1) & (2) & (3) & (4) & (5) & $(6)_{-}$ & (7) & (8) & (9) \\
\hline[ & ] & (1) & (2) & (3) & (4) & (5) & (6) & (7) & (8) & (9) \\
\hline[ & ] & (1) & (2) & (3) & (4) & $(5)_{-}$ & $(6)_{-}$ & (7) & (8) & (9) \\
\hline[ & ] & (1) & (2) & (3) & (4) & (5) & (6) & (7) & (8) & (9) \\
\hline[ & ] & (1) & (2) & (3) & (4) & (5) & (6) & (7) & (8) & (9) \\
\hline[ & ] & (1) & (2) & (3) & (4) & (5) & (6) & (7) & (8) & (9) \\
\hline [ & ] & (1) & (2) & (3) & (4) & (5) & (6) & (7) & (8) & (9) \\
\hline [ & ] & (1) & (2) & (3) & (4) & (5) & (6) & (7) & (8) & (9) \\
\hline [ & ] & (1) & (2) & (3) & (4) & (5) & (6) & (7) & (8) & (9) \\
\hline
\end{tabular}


CREATIVITY:

(continued)
The degree to which the design is creative, using your own subjective definition of creativity.

\begin{tabular}{|c|c|c|c|c|c|c|c|c|c|c|}
\hline \multicolumn{11}{|c|}{$\begin{array}{l}\text { Project } \\
\text { Number }\end{array}$} \\
\hline [ & ] & (1) & (2) & (3) & (4) & (5) & (6) & (7) & (8)_ & (9)_ \\
\hline[ & ] & (1) & (2) & (3) & (4) & (5) & (6) & (7) & (8) & (9) \\
\hline[ & ] & (1) & (2) & (3) & (4) & (5) & (6) & (7) & (8) & (9)_ \\
\hline [ & ] & (1) & (2) & (3) & (4) & (5) & (6) & (7) & (8) & (9) \\
\hline[ & ] & (1) & (2) & (3) & (4) & (5) & (6) & (7) & (8) & (9) \\
\hline [ & ] & (1) & (2) & (3) & (4) & (5) & (6) & (7) & (8) & (9) \\
\hline[ & ] & (1) & (2) & (3) & (4) & (5) & (6) & (7) & (8) & (9) \\
\hline [ & ] & (1) & (2) & (3) & (4) & (5) & (6) & (7) & (8) & (9) \\
\hline[ & ] & (1) & (2) & (3) & (4) & (5) & (6) & (7) & (8) & (9) \\
\hline [ & ] & (1) & (2) & (3) & (4) & (5) & (6) & (7) & $(8)_{-}$ & (9) \\
\hline[ & ] & (1) & (2) & (3) & (4) & (5) & (6) & (7) & (8) & (9) \\
\hline[ & ] & (1) & (2) & (3) & (4) & (5) & (6) & (7) & (8) & (9) \\
\hline[ & ] & (1) & (2) & (3) & (4) & (5) & (6) & (7) & (8) & (9) \\
\hline [ & ] & (1) & (2) & (3) & (4) & (5) & $(6)_{-}$ & (7) & $(8)_{-}$ & (9) \\
\hline[ & ] & (1) & (2) & (3) & (4) & (5) & (6) & (7) & (8) & (9) \\
\hline[ & ] & (1) & (2) & (3) & (4) & (5) & (6) & (7) & (8) & (9) \\
\hline [ & ] & (1) & (2) & (3) & (4) & (5) & (6) & (7) & (8) & (9) \\
\hline[ & ] & (1) & (2) & (3) & (4) & (5) & (6) & (7) & (8) & (9) \\
\hline
\end{tabular}

The following list of consecutive numbers $(1-36)$ has been provided for your convenience in crossing off projects during the rating process, if desired:

$$
\begin{array}{lllllllllllllllllll}
1 & 2 & 3 & 4 & 5 & 6 & 7 & 8 & 9 & 10 & 11 & 12 & 13 & 14 & 15 & 16 & 17 & 18 & 19 \\
20 & 21 & 22 & 23 & 24 & 25 & 26 & 27 & 28 & 29 & 30 & 31 & 32 & 33 & 34 & 35 & 36
\end{array}
$$


Judge No.

NOVELTY:

The degree to which the use of materials and/or design elements is novel.

Please rate ( _ _ ) each project from VERY LOW to VERY HIGH on the aspect described above.

Rate projects RELATIVE TO ONE ANOTHER, not according to some absolute standard for excellence. Consider projects in ANY RANDOM ORDER, and indicate the number of the project being rated [ $1-36]$ in the bracket provided on the left.

VERY LOW

VERY HIGH

\begin{tabular}{|c|c|c|c|c|c|c|c|c|c|c|}
\hline \multicolumn{10}{|c|}{$\begin{array}{l}\text { Project } \\
\text { Number }\end{array}$} & \\
\hline[ & ] & (1)__ & (2) & (3) & (4) & (5) & (6) & (7) & $(8)$ & (9) \\
\hline[ & ] & (1) & (2) & (3) & (4) & (5) & (6) & (7) & (8) & (9) \\
\hline [ & ] & (1) & (2) & (3) & (4) & (5) & (6) & (7) & (8) & (9) \\
\hline[ & ] & (1) & (2) & (3) & (4) & (5) & (6) & (7) & (8) & (9) \\
\hline[ & ] & (1) & (2) & (3) & (4) & (5) & (6) & (7) & $(8)_{-}$ & (9) \\
\hline [ & ] & (1) & (2) & (3) & (4) & (5) & (6) & (7) & (8) & (9) \\
\hline [ & ] & (1) & (2) & (3) & (4) & (5) & (6) & (7) & $(8)_{-}$ & (9) \\
\hline [ & ] & (1) & (2) & (3) & (4) & (5) & (6) & (7) & $(8)_{-}$ & (9) \\
\hline[ & ] & (1) & (2) & (3) & (4) & (5) & (6) & (7) & (8) & (9) \\
\hline [ & ] & (1) & (2) & (3) & (4) & (5) & (6) & (7) & $(8)_{-}$ & (9) \\
\hline [ & ] & (1) & (2) & (3) & (4) & (5) & (6) & (7) & $(8)_{-}$ & (9) \\
\hline [ & ] & (1) & (2) & (3) & (4) & (5) & (6) & (7) & $(8)_{-}$ & (9) \\
\hline [ & ] & (1) & $(2)_{-}$ & (3) & (4) & (5) & (6) & (7) & $(8)_{-}$ & (9) \\
\hline [ & ] & (1) & $(2)_{-}$ & (3) & (4) & (5) & (6) & (7) & $(8)_{-}$ & (9) \\
\hline [ & ] & (1) & $(2)_{-}$ & (3) & (4) & (5) & (6) & (7) & (8) & (9) \\
\hline [ & ] & (1) & $(2)_{-}$ & (3) & (4) & (5) & (6) & (7) & $(8)_{-}$ & (9) \\
\hline [ & ] & (1) & (2) & (3) & (4) & (5) & (6) & (7) & (8) & (9) \\
\hline [ & ] & (1) & (2) & (3) & (4) & (5) & (6) & (7) & (8) & (9)_ \\
\hline
\end{tabular}


NOVELTY:

(continued)
The degree to which the use of materials and/or design elements is novel.

Project

Number

\begin{tabular}{|c|c|c|c|c|c|c|c|c|c|}
\hline ] & (1) & (2) & $(3)$ & (4) & (5) & (6) & (7) & (8) & (9) \\
\hline ] & (1) & (2) & (3) & (4) & (5) & (6) & (7) & (8) & (9) \\
\hline ] & (1) & (2) & (3) & (4) & (5) & (6) & (7) & (8) & (9) \\
\hline ] & (1) & (2) & (3) & (4) & (5) & (6) & (7) & (8) & (9) \\
\hline ] & (1) & (2) & (3) & (4) & (5) & (6) & (7) & (8) & (9) \\
\hline ] & (1) & (2) & (3) & (4) & (5) & (6) & (7) & (8) & (9) \\
\hline ] & (1) & (2) & (3) & (4) & (5) & (6) & (7) & (8) & (9) \\
\hline$]$ & (1) & (2) & (3) & (4) & (5) & (6) & (7) & (8) & (9) \\
\hline ] & (1) & (2) & (3) & (4) & (5) & (6) & (7) & (8) & (9) \\
\hline ] & (1) & (2) & (3) & (4) & (5) & (6) & (7) & (8) & (9) \\
\hline ] & (1) & (2) & (3) & (4) & (5) & (6) & (7) & (8) & (9) \\
\hline ] & (1) & (2) & (3) & (4) & (5) & (6) & (7) & (8) & (9) \\
\hline$]$ & (1) & (2) & (3) & (4) & (5) & (6) & (7) & (8) & (9) \\
\hline$]$ & (1) & (2) & (3) & (4) & (5) & (6) & (7) & (8) & (9) \\
\hline$]$ & (1) & (2) & (3) & (4) & (5) & (6) & (7) & (8) & (9) \\
\hline ] & (1) & (2) & (3) & (4) & (5) & (6) & (7) & (8) & (9) \\
\hline$]$ & (1) & (2) & (3) & (4) & (5) & (6) & (7) & (8) & (9) \\
\hline$]$ & (1) & (2) & (3) & (4) & (5) & (6) & (7) & (8) & (9) \\
\hline
\end{tabular}

The following list of consecutive numbers $(1-36)$ has been provided for your convenience in crossing off projects during the rating process, if desired:

$$
\begin{array}{lllllllllllllllllll}
1 & 2 & 3 & 4 & 5 & 6 & 7 & 8 & 9 & 10 & 11 & 12 & 13 & 14 & 15 & 16 & 17 & 18 & 19 \\
20 & 21 & 22 & 23 & 24 & 25 & 26 & 27 & 28 & 29 & 30 & 31 & 32 & 33 & 34 & 35 & 36
\end{array}
$$




\section{APPENDIX E}

Correspondence with Judges 


\section{Virginia}

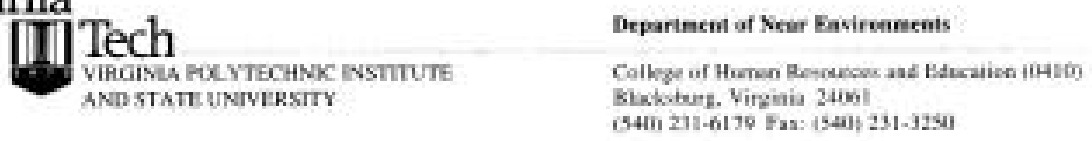

September 25, 1999

\section{Dear}

Becanse of your copertise in interior design, I am writing to ack for your help with a restarch project currently in progress as Virginia Tech. It requires experts in the profession to view a display of student projects and provide indegendent ratings on various aspects of project merit.

Two separate one-day Judging Sessions have been scheduled for Friday, Qctober $8^{4}$ and Friday, Oetober $15^{*}$ at Virginia Tech in Blackstourg. VA.

The projects will be ce display beginaing at $9 \mathrm{zm}$. on the schodulod diate. Esch expert jodze may come by at a extrveniens pre-aranged time during the diny to complete the untimed rating process, which requires spproxinstely oee and one-half hours.

In the next few days I will contact you by telephose to ask you to participate as a judge in the study. Af that time I will be hapgy to answer any further qoestions you lave sbeut the research project or the judging session. I would also like to schedule a comvenient time during the one-day session of your choice to complete the rating process.

I hope that you will azrex 10 participate in this important interior design research projoct. I look forward to talking with you sooe. Thank you foe your assistance.

Sinoerely,

April D. Allen

Joan McLain-Kark

Major Advisor 
Virginia

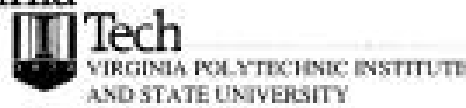

Deparinent of Near Remirsanents

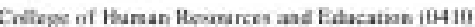

Blackstatt. Viezinie 2 anti

(509) $231-6179$ Fas: 15400 231-3250

October 26, 1999

Dear

I would like to take this opportunity to thank you for taking time from your busy schedule to participate in my study at Virginia Tech. Without the generosity of professionals such as you my study could not have been completed.

I am looking at a correlation between visualization and creativity. The creativity score will come from the rating sessions that you participated in.

Thank you again for all your support.

Sincerely,

Aprii D. Allen 


\section{APPENDIX F}

Instructions for the Project Judging Session 
Instructions for the Project Judging Session

Your task is to rate the interior design projects displayed in this room on 3 aspects of merit (Dimensions of Judgment) as described on the rating sheets. Please complete these subjective ratings independently, without discussion or collaboration.

You may proceed at your own pace to complete the judging tasks as outlined below. Since it is imperative that all ratings be completed for all projects, no time limits will be imposed for the judging session.

1. Preparing for Judging: A table has been provided for your convenience in reading and examining the judging materials provided on the clipboard:
a. Project Statement
b. Dimensions of Judgment for Interior Design Projects
c. 3 Rating Sheets arranged in pre-determined order

2. Previewing Projects: Before beginning the actual judging process, take some time to browse through the display to familiarize yourself with the projects and to establish your own impression as to overall range of project merit represented.

3. Rating Projects: Procedures to Follow

a. Rating sheets are arranged on the clipboard in a pre-determined order which must not be altered. Rate all projects on the dimension described on the first sheet before proceeding to the second sheet.

b. It is important that you select projects for rating in a random order of your own choice rather than advancing straight through the display. As you proceed, please indicate the project being rated by writing its corresponding number in the bracket provided to the left of each rating scale.

c. Please rate projects on the dimension described on the sheet by placing a checkmark (__ $)$ at the appropriate position on the nine-point scale ( $1=$ VERY LOW; $9=$ VERY $\mathrm{HIGH}$ ). It is important that you rate projects relative to one another, not according to some absolute standard for excellence.

d. When all projects have been rated on the first dimension, remove the first rating sheet from the clipboard and place it behind all other sheets. Then, proceed to the second sheet and repeat the rating process on the second dimension, again selecting projects in any random order. Repeat the process for the third rating sheet.

4. Submitting Ratings: When finished with all rating sheets, please make sure all project numbers and ratings are complete. When you are certain that nothing has been left blank, return the clipboard to the researcher. Thank You! 


\section{APPENDIX G}

Demographics Sheet 


\section{Some Questions About Your Background}

Judge No.

A. What is your current principal employment?

[ ] INTERIOR DESIGNER

[ ] INTERIOR DESIGN EDUCATOR

[ ] INTERIOR DESIGN GRADUATE STUDENT

B. Whether a designer or an educator, how would you categorize your interior design focus and expertise?

[ ] PRIMARILY CONTRACT

[ ] PRIMARILY RESIDENTIAL

[ ] EQUALLY CONTRACT/RESIDENTIAL

C. What degrees do you hold?
DEGREE
DATE
INSTITUTION
MAJOR

D. What academic discipline or program area best describes your educational training in interior design?

[ ] ARCHITECTURE

[ ] ART

[ ] INTERIOR DESIGN

[ ] OTHER? Describe:

E. Whether a designer or an educator, how many years have you been employed full-time in the interior design profession?

$\begin{array}{lll}{[} & ] & 0-5 \text { YEARS } \\ {[} & ] & 6-10 \text { YEARS } \\ {[} & ] & 11-15 \text { YEARS } \\ {[} & ] & 16-20 \text { YEARS } \\ {[} & ] & 21-25 \text { YEARS } \\ {[} & ] & 26-30 \text { YEARS } \\ {[} & & 31 \text { YEARS OR MORE }\end{array}$

F. Are you?

[ ] MALE [ ] FEMALE

G. What difficulties, if any, did you encounter during this judging session? For example, were there problems with:

INSTRUCTIONS? Describe:

DIMENSIONS OF JUDGMENT (rating criteria)? Describe:

PHYSICAL ENVIRONMENT? Describe:

FATIGUE? Describe:

OTHER? Describe: 


\section{APPENDIX H}

Isham's Visualization Assessment 


\section{GROUP ONE \\ Directions:}

Use the given 2D 83D drawings to identify the correct fifth view from the four options. White arrowhead shows the given 3D view. Black arrowhead shows orientation of the desired fitth view. Use the work area for sketching.

\section{Example:}

1)

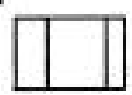

B
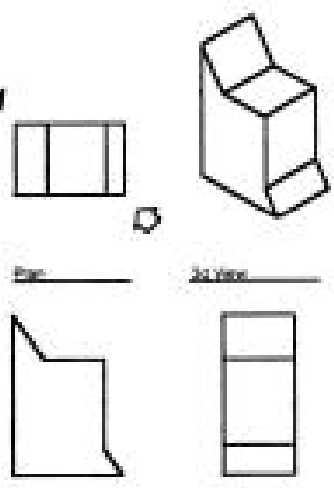

$n$

$$
\text { Dow }
$$

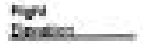

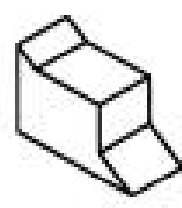

pates.<smiles>C1CC2CC3CC1CC23</smiles>

anos:

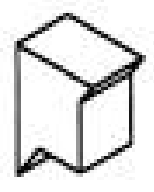

axtent<smiles>C1C2CC3CC1CC(C2)C3</smiles>

swese

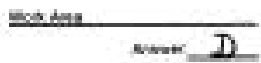

5 

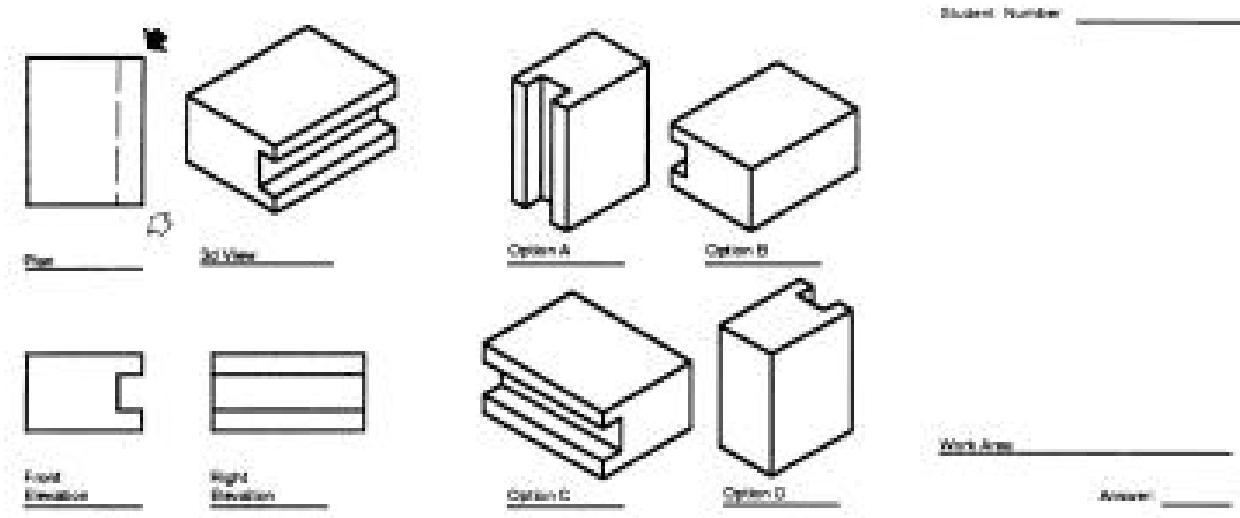

(2)
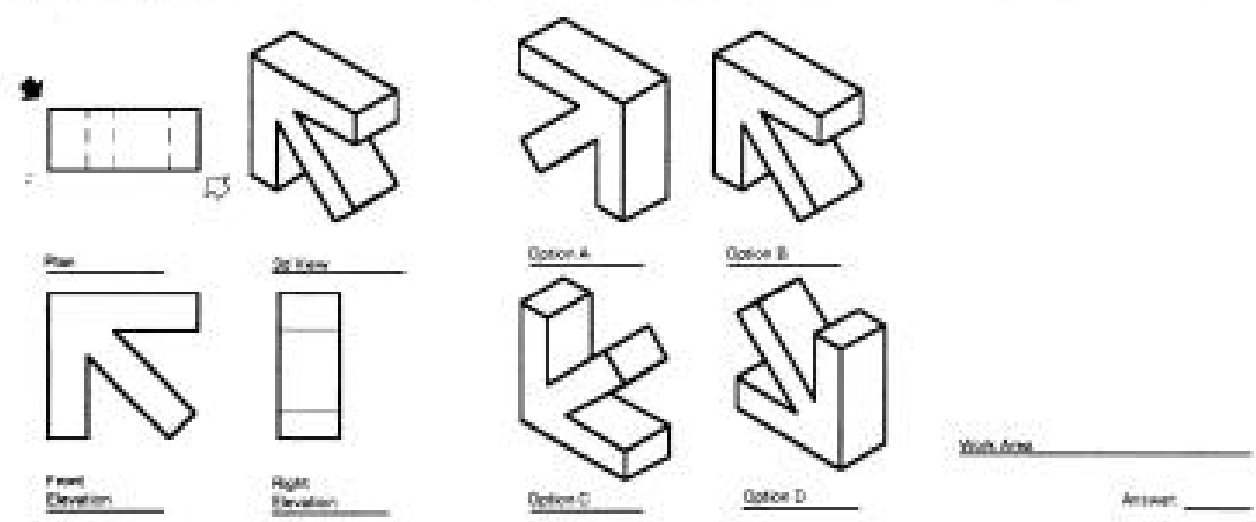

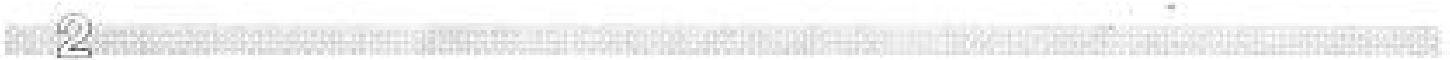
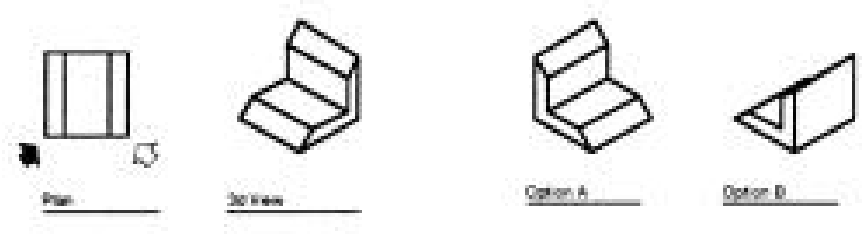

gas A

anso 1
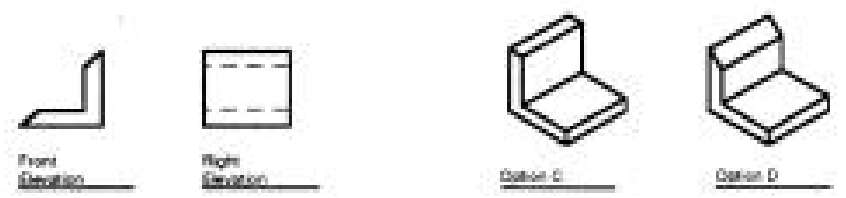

Wuatere

$\underline{0-10}$

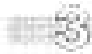



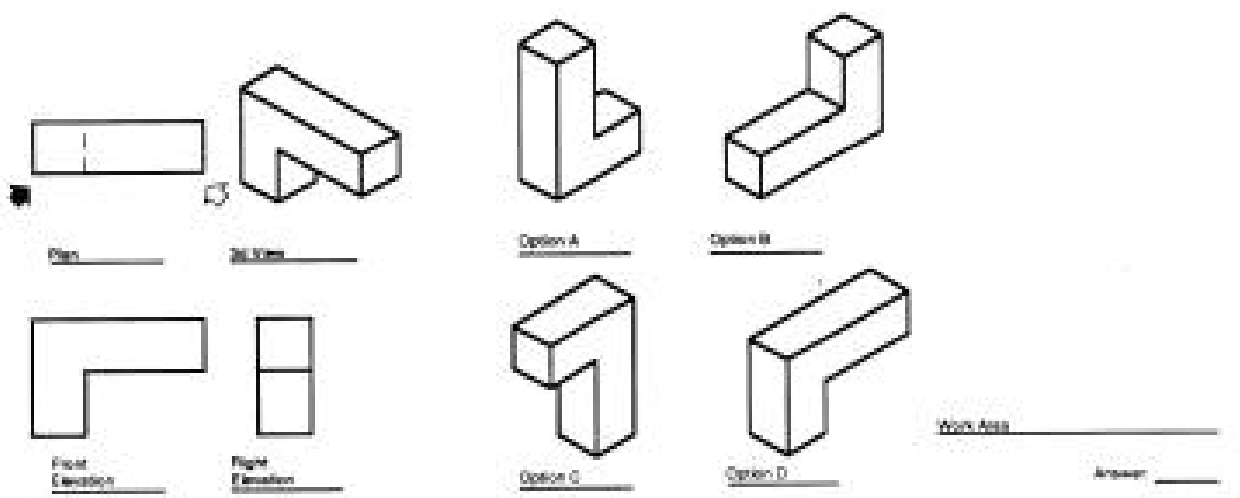

수눈 4

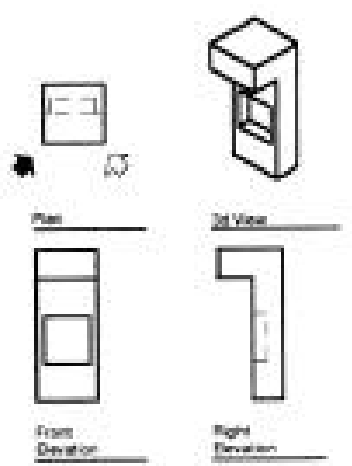

园
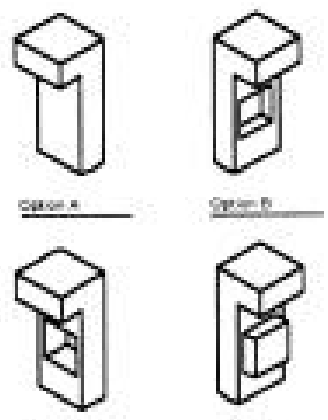

gareng

gonos

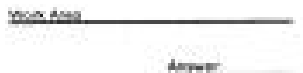

표
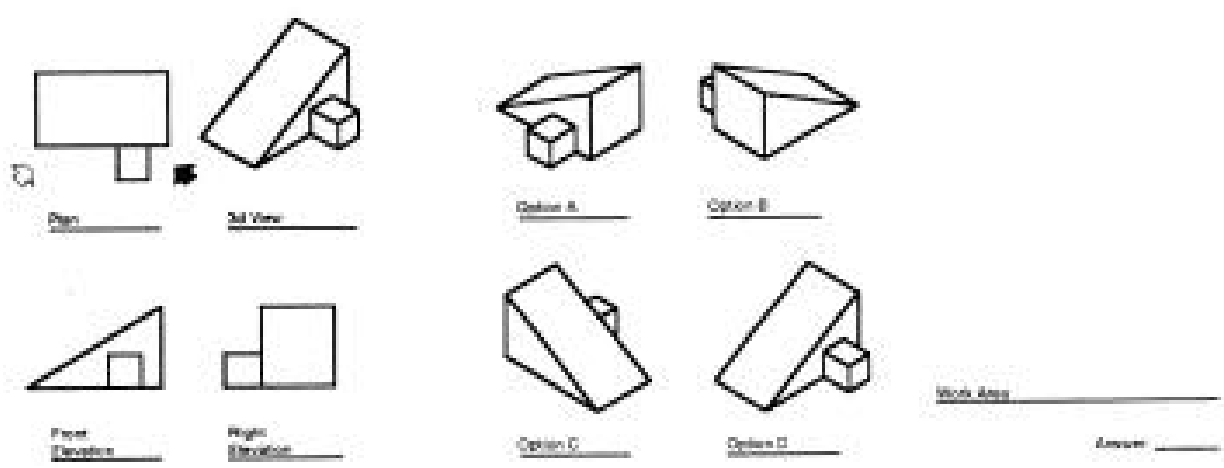

(11) (ix) (i) 

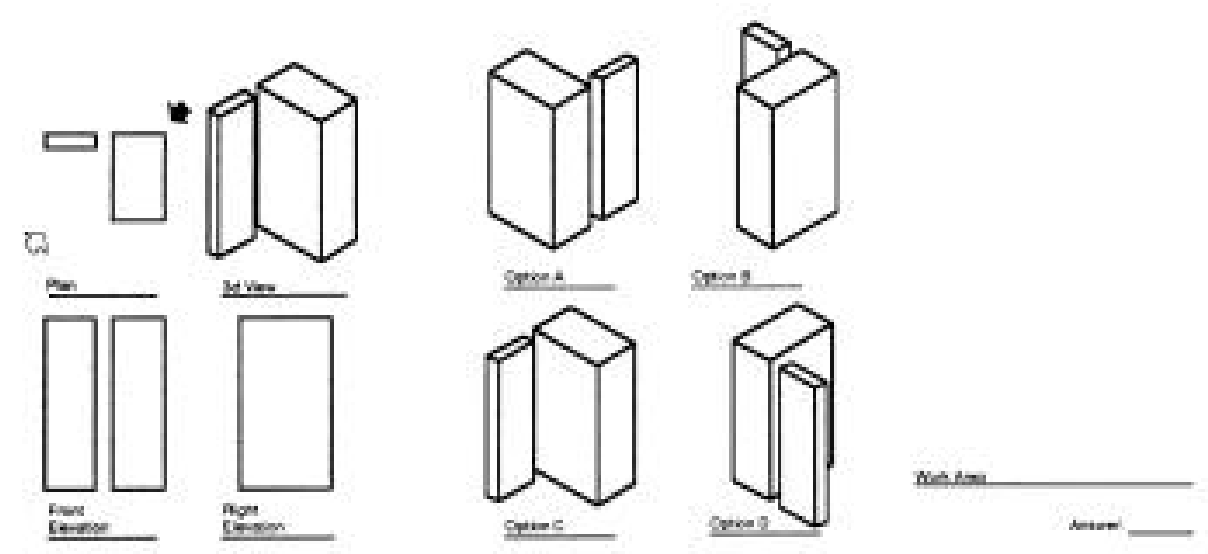

7
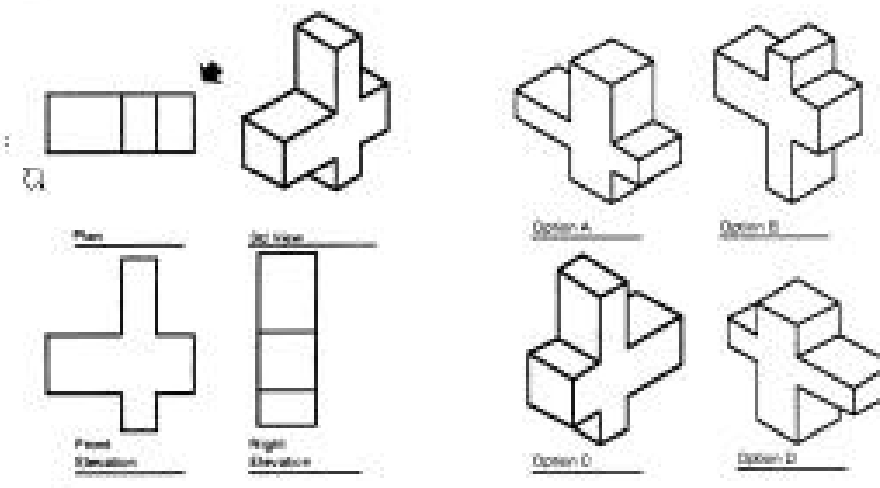

-

(8)
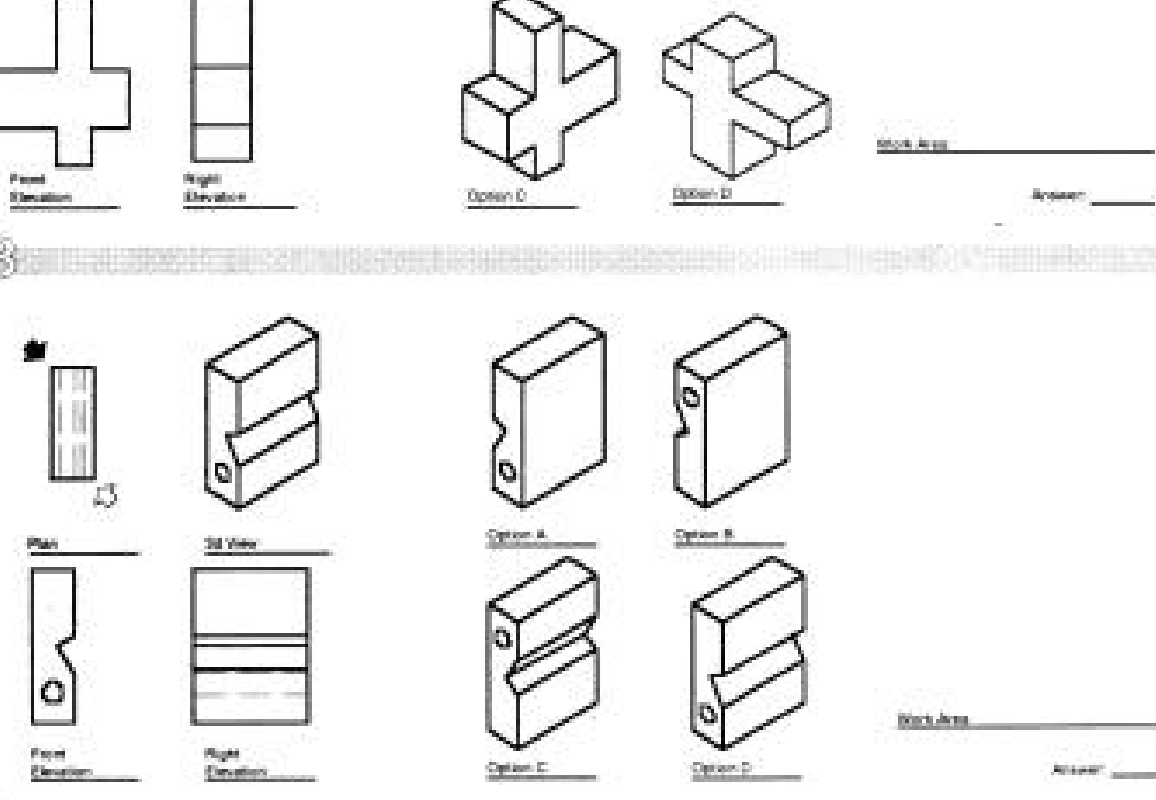

(9) 
56

Dr B
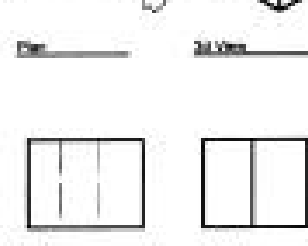

Enove
Strion

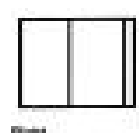

now
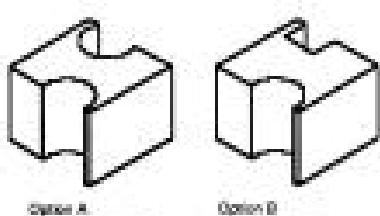

Oarone

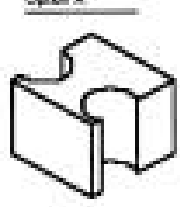

gane

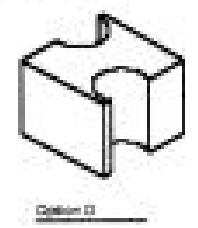

maseses

tres

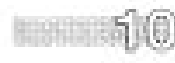
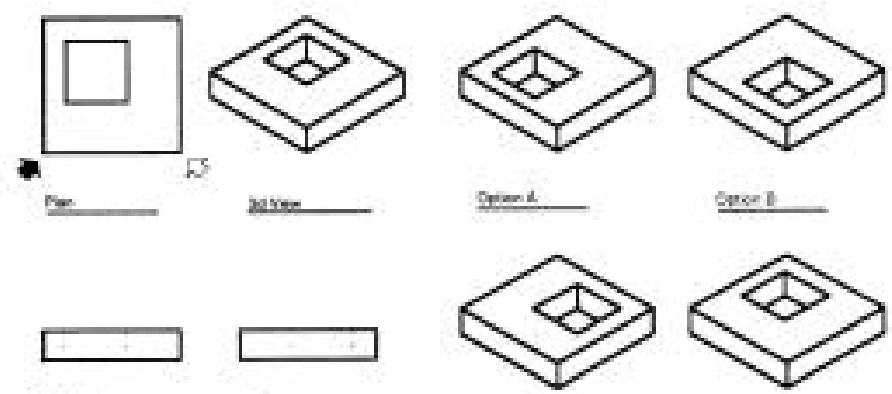

Gever
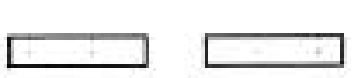

tion

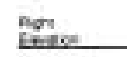

gemenc.

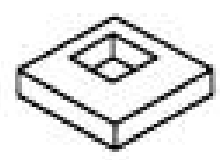

ow:D D

wades

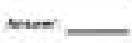

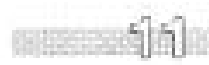
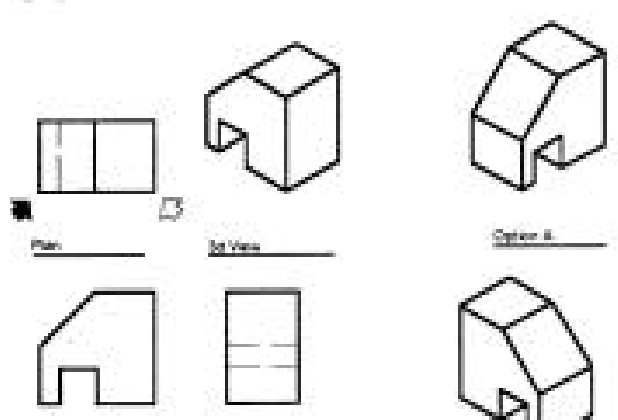

$\gamma_{1}$

Fere
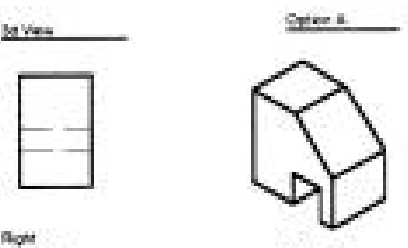

(1)

moxke

gye

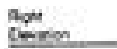



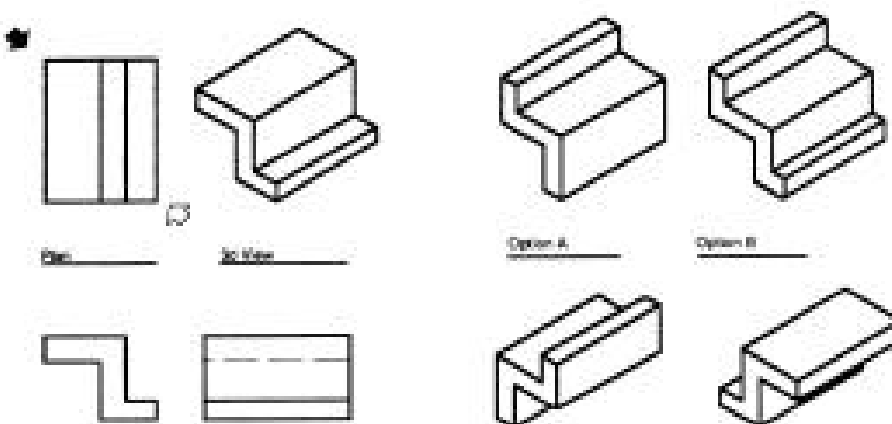

ave
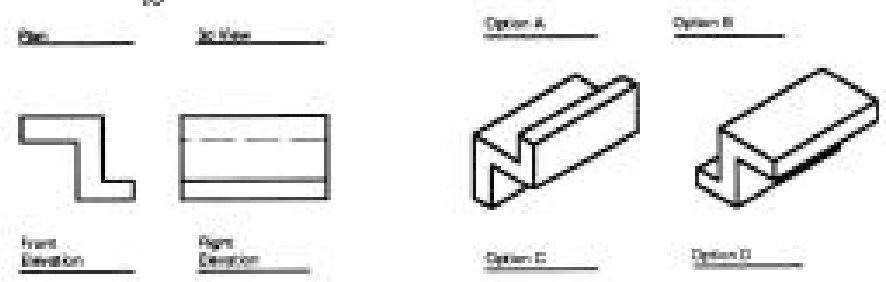

gate

$\operatorname{Brang} \mathrm{B}$

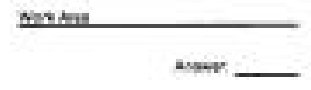

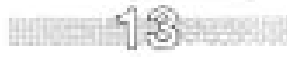
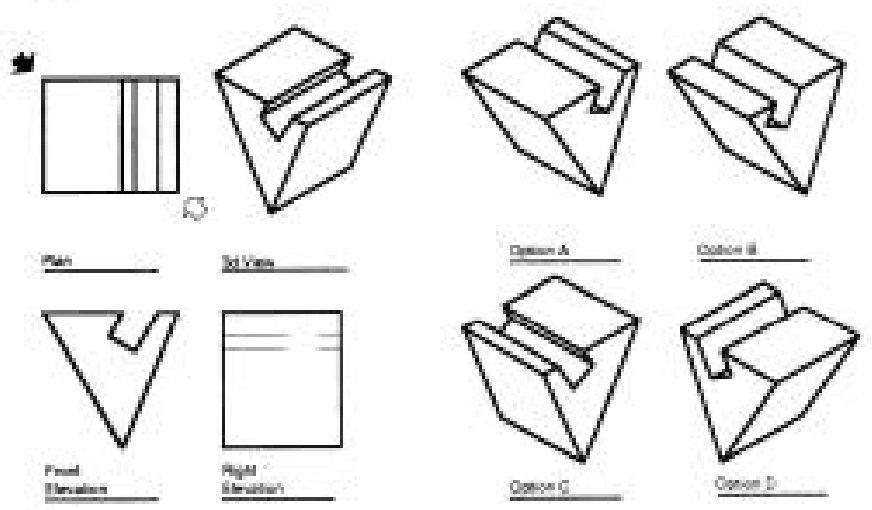

bistore

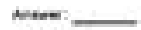

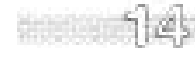
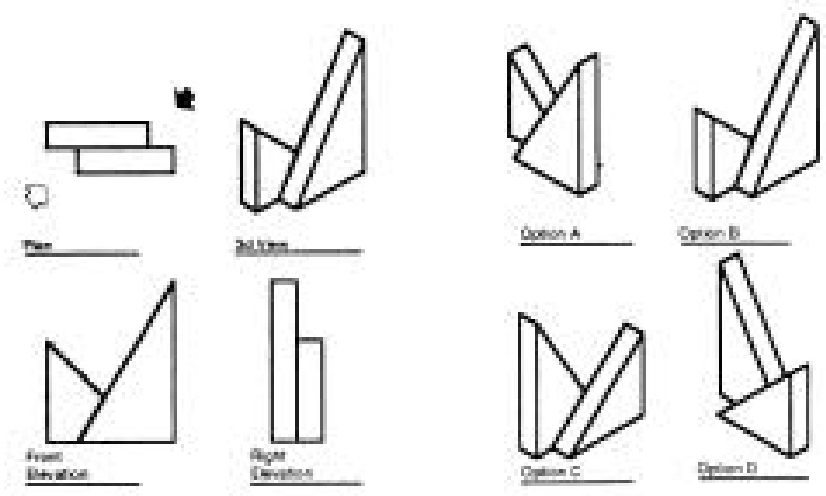

\section{주마. 518}



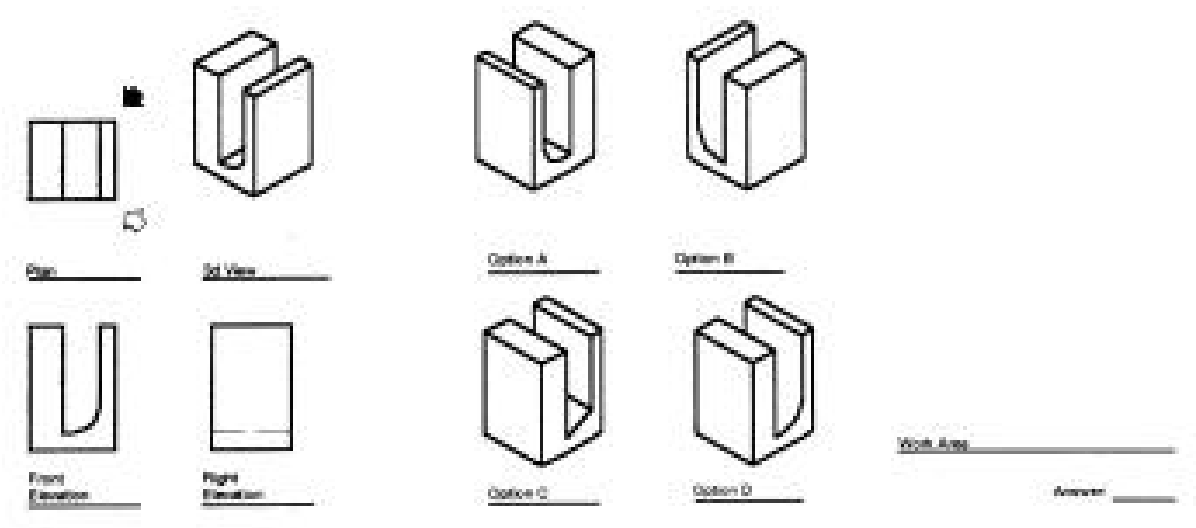

\section{91.5}
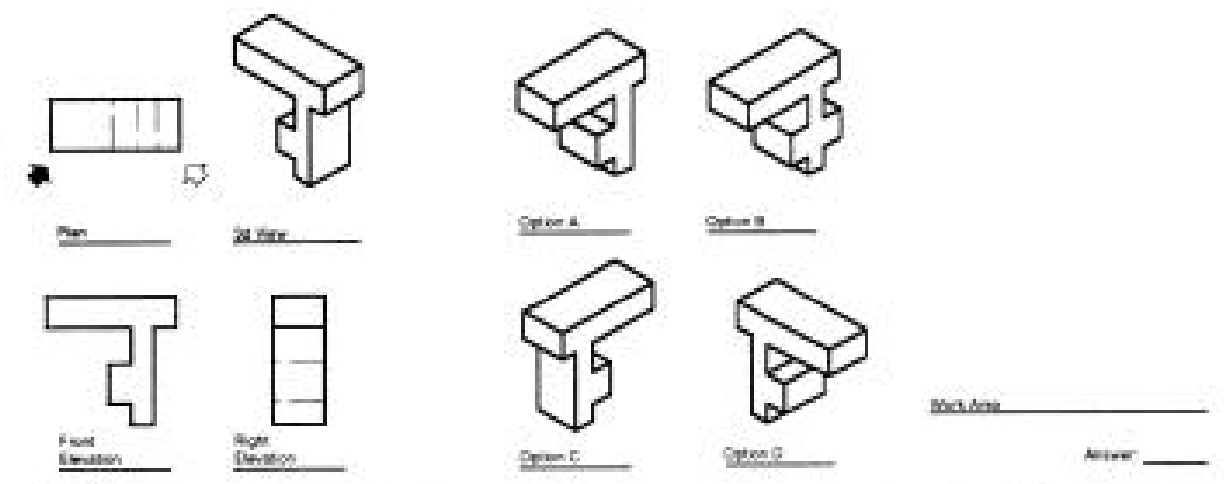

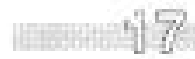
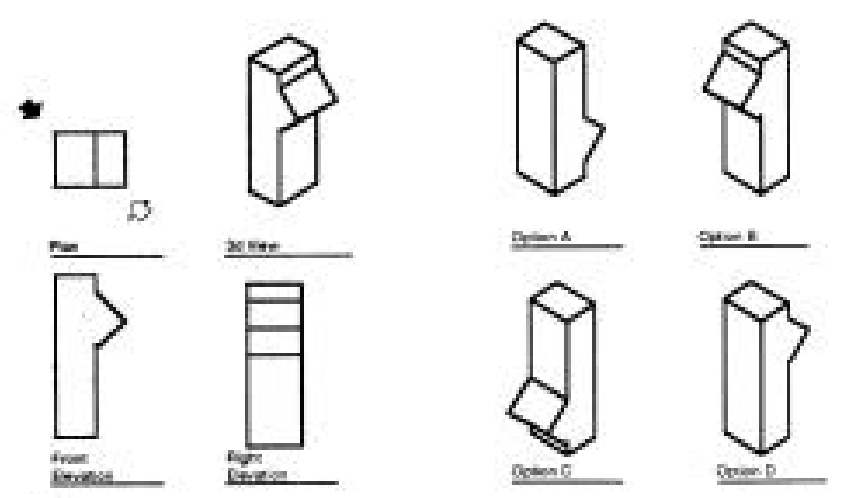

matos

tix 


\section{GROUP TWO \\ Directions:}

Use the given $3 \mathrm{D}$ view to identify the incorrect $2 \mathrm{D}$ view trom the three options.

\section{Example:}
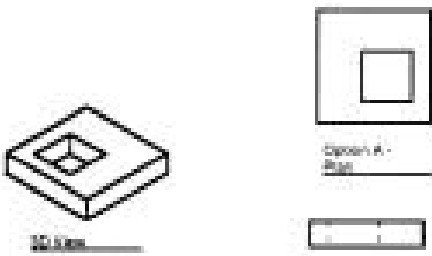

Gointo-

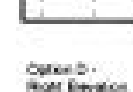

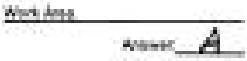



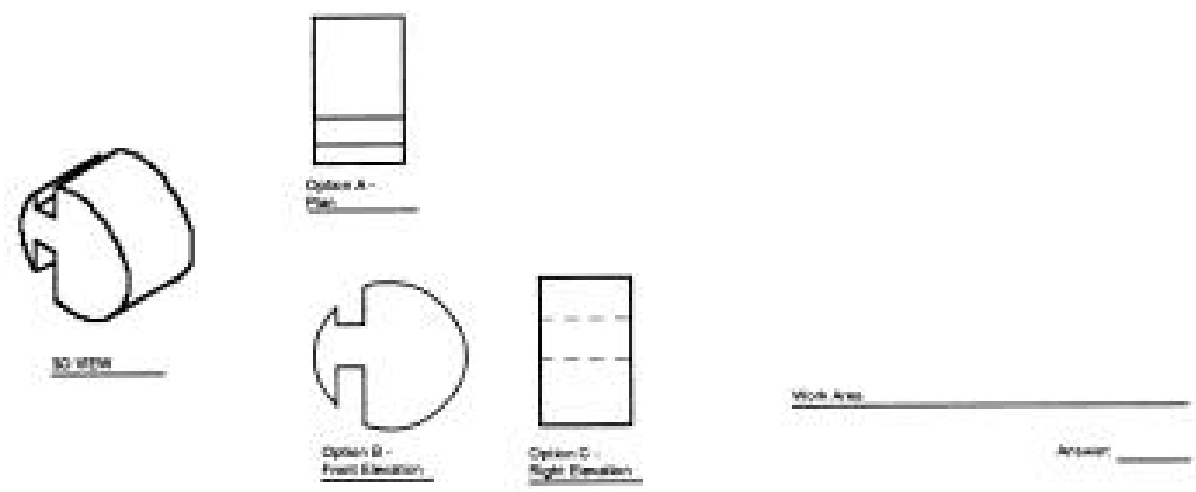

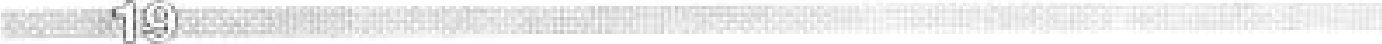
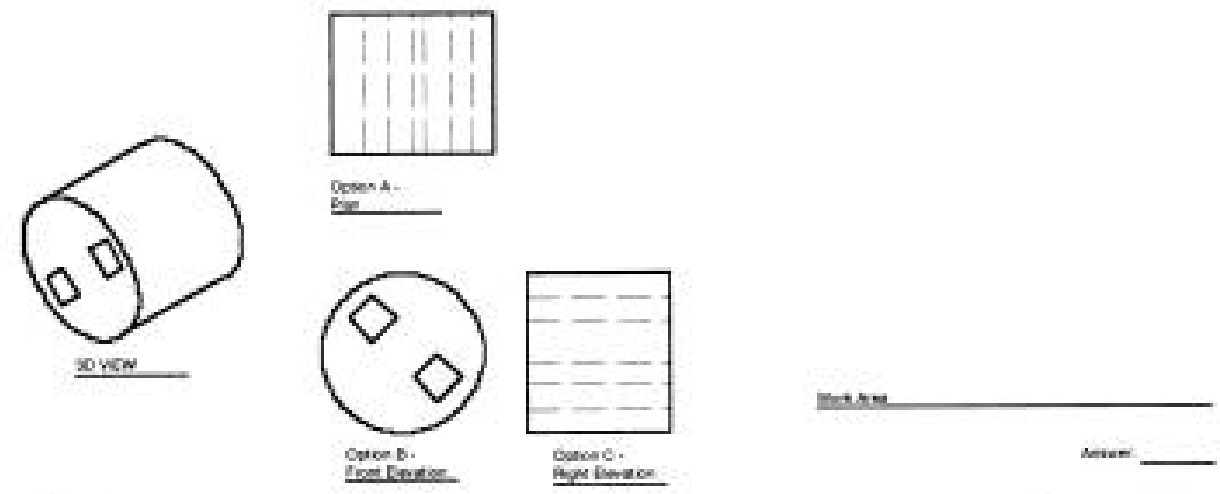

Ait: 40
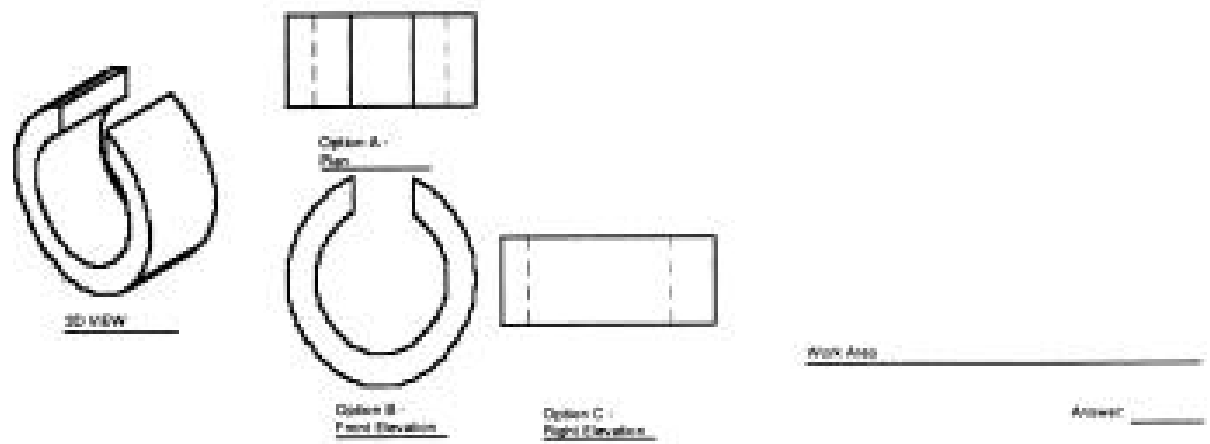

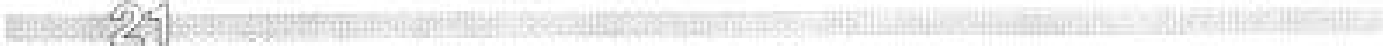



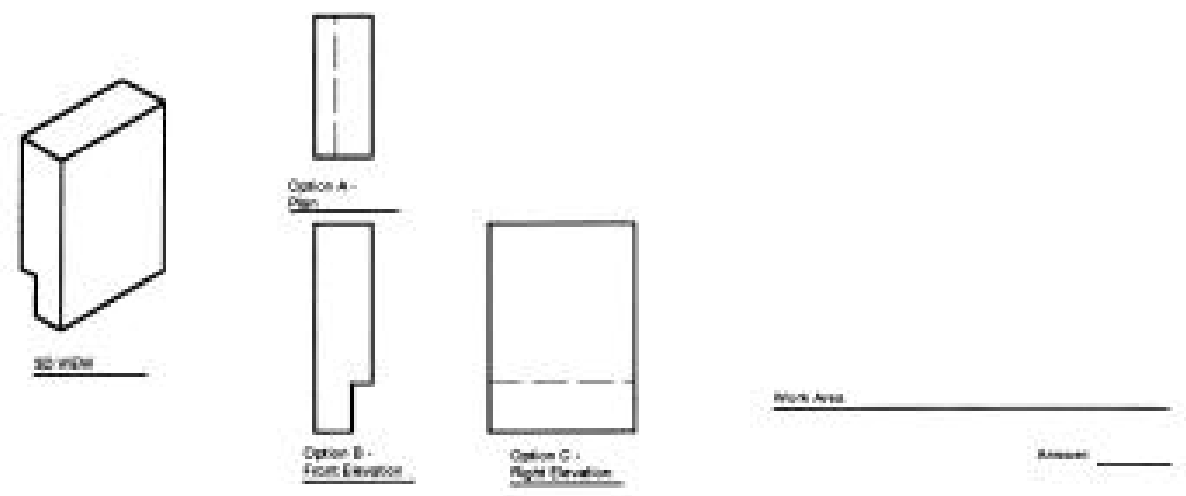

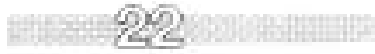
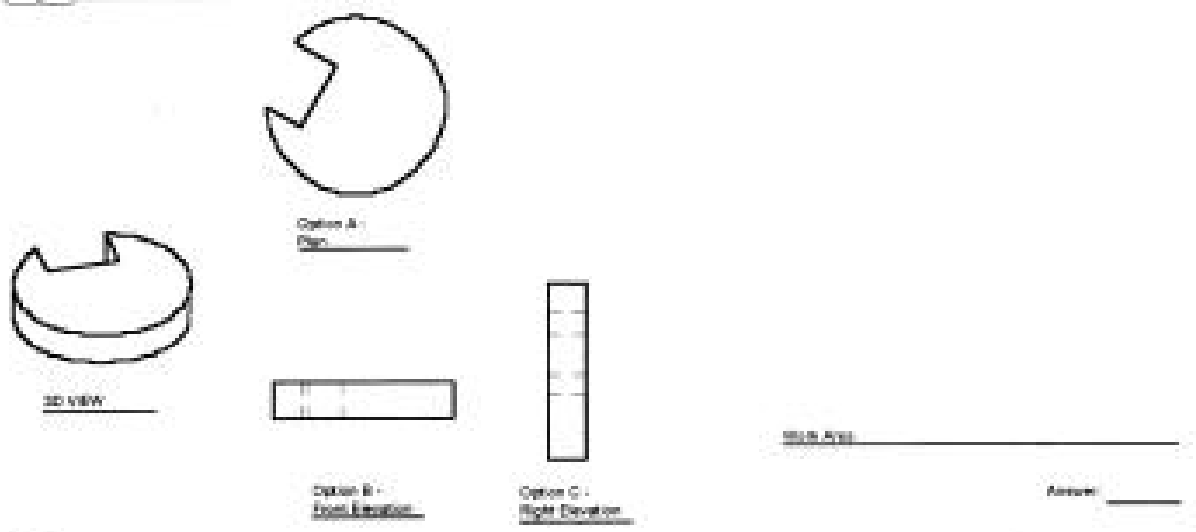

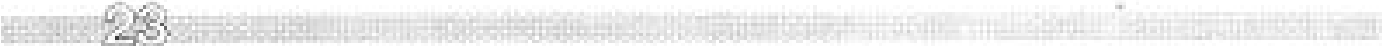
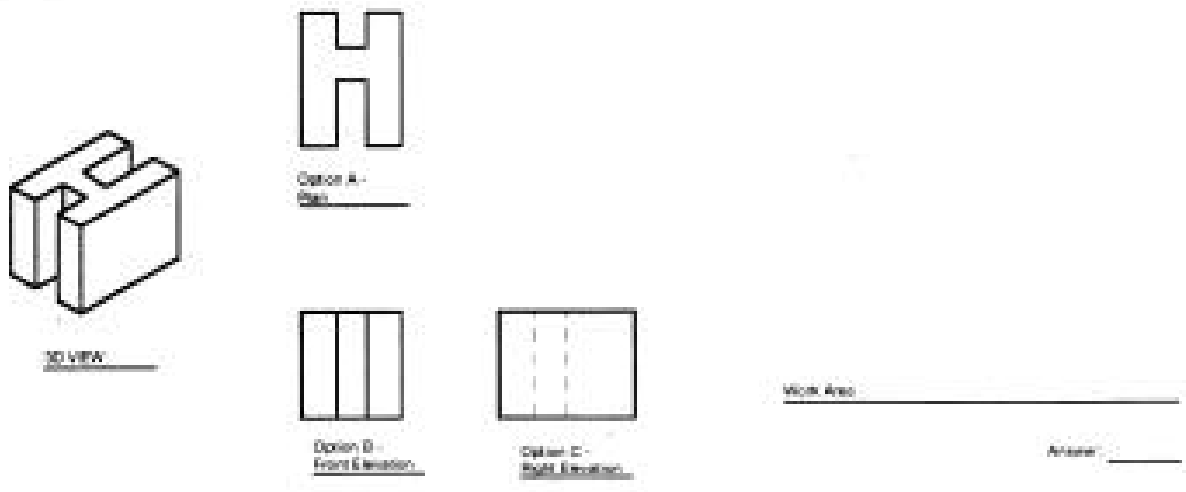

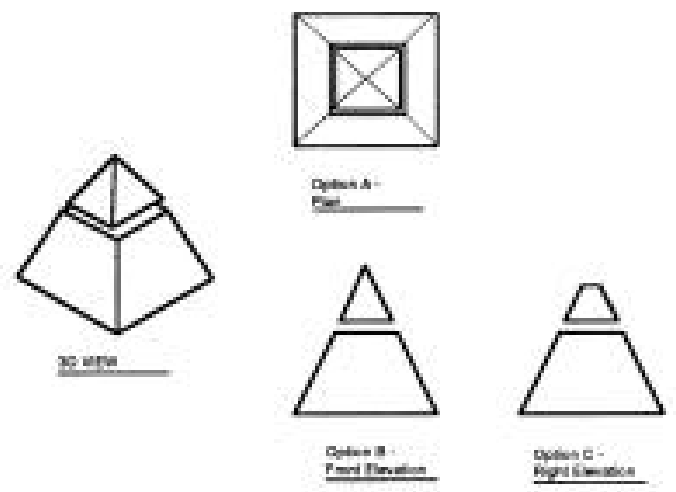

Wovere
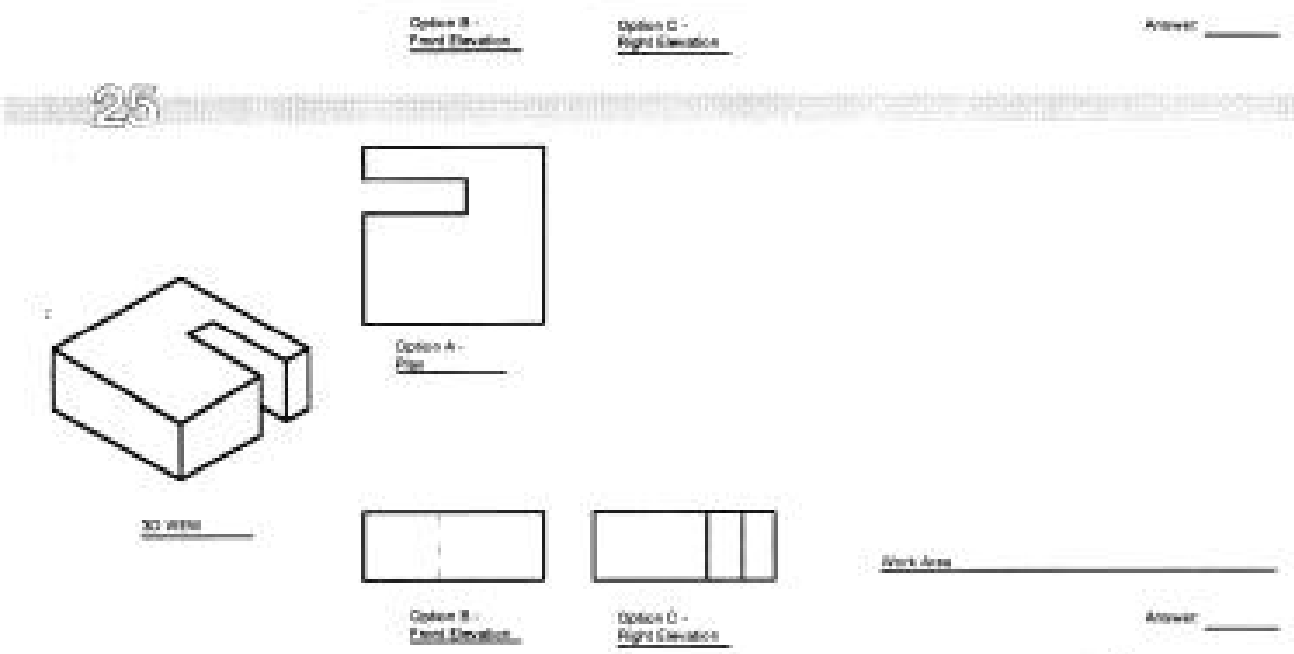

2010
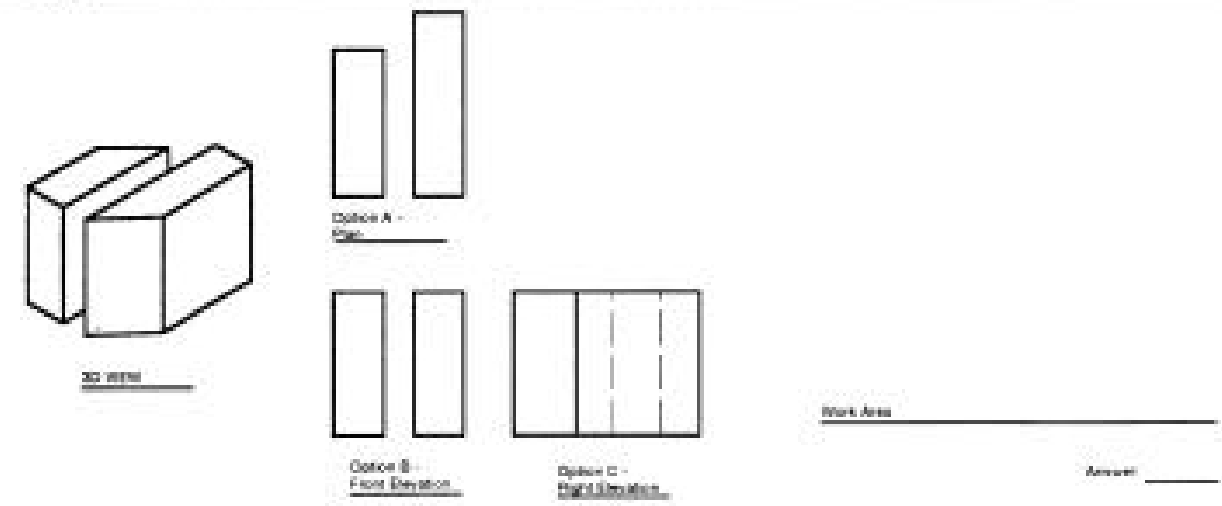


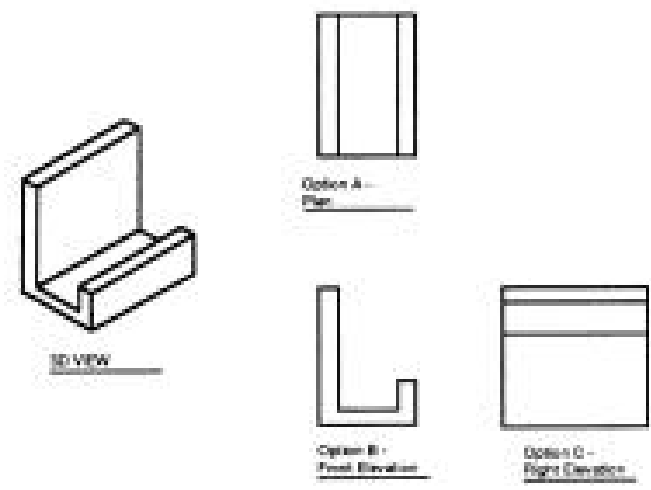

Wudtere

veractices:

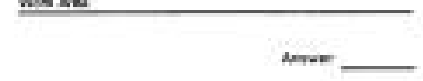

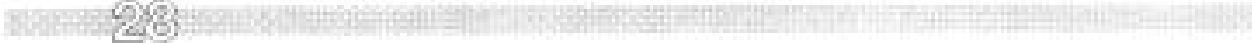
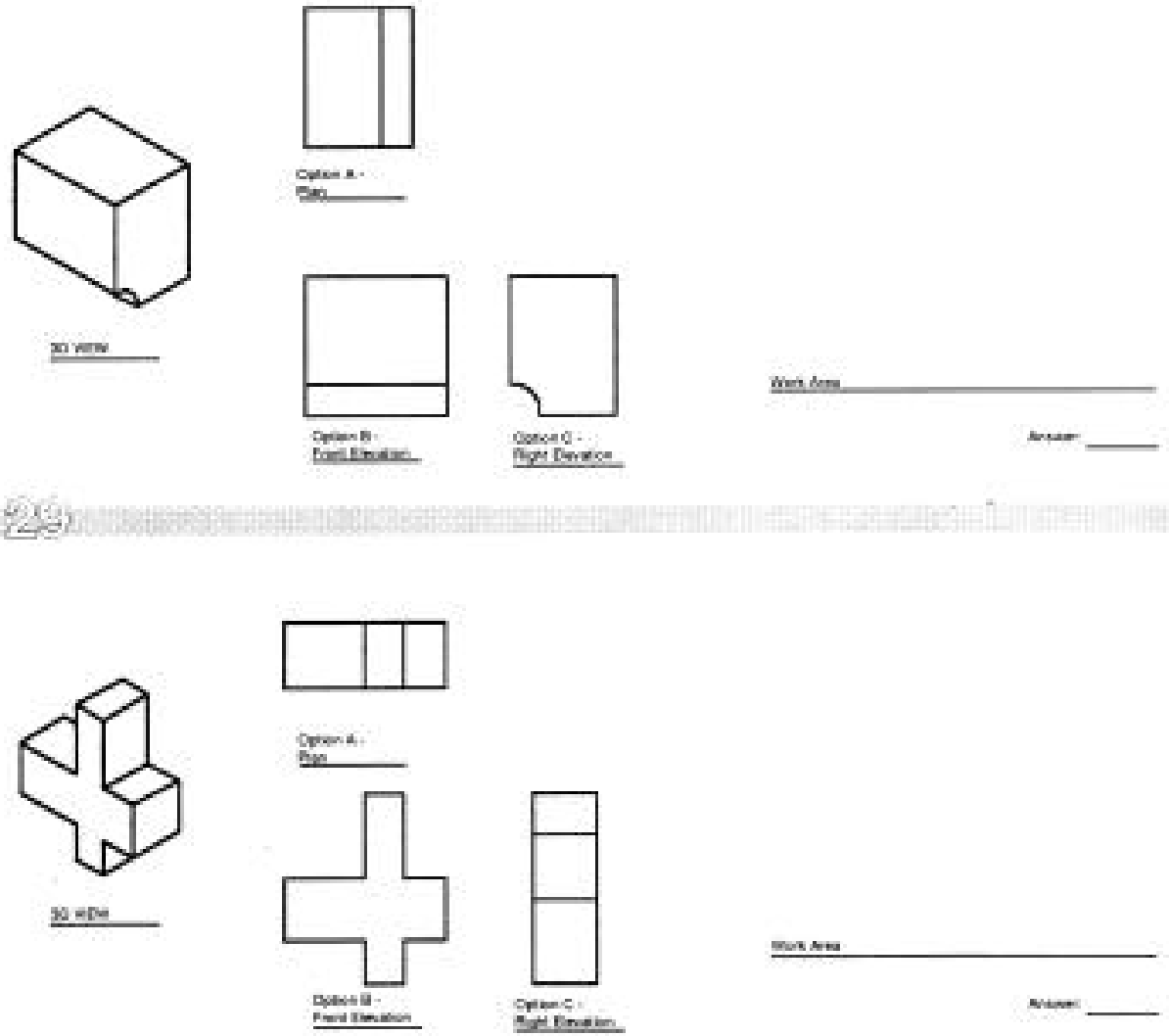

(2) 


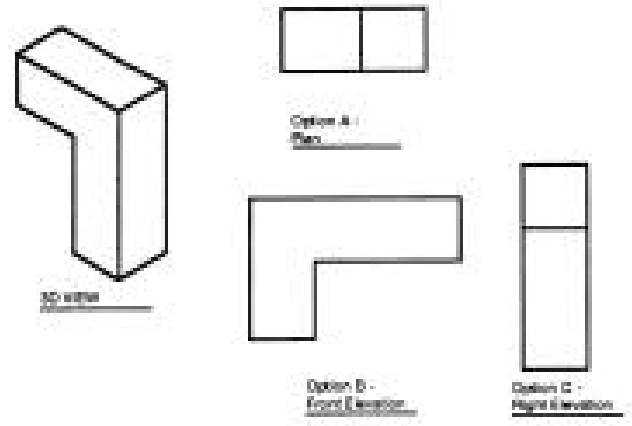

incors

fonctione

secionitus

- 85
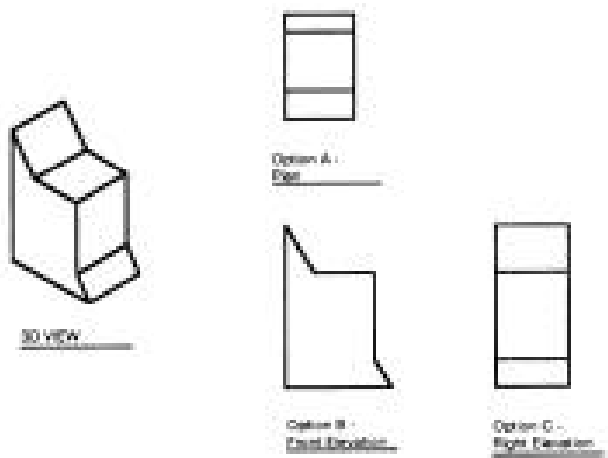

prestak

stetert-

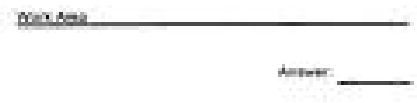

-31 3
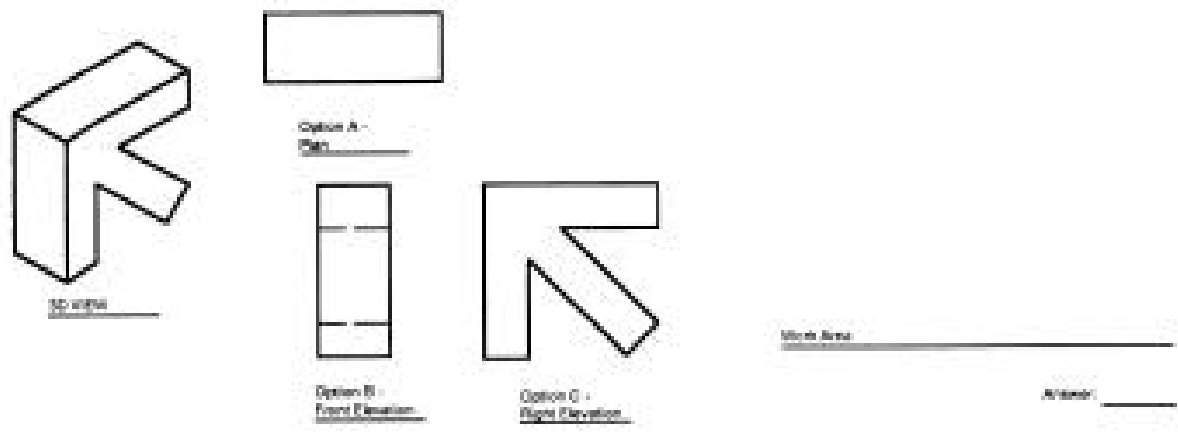

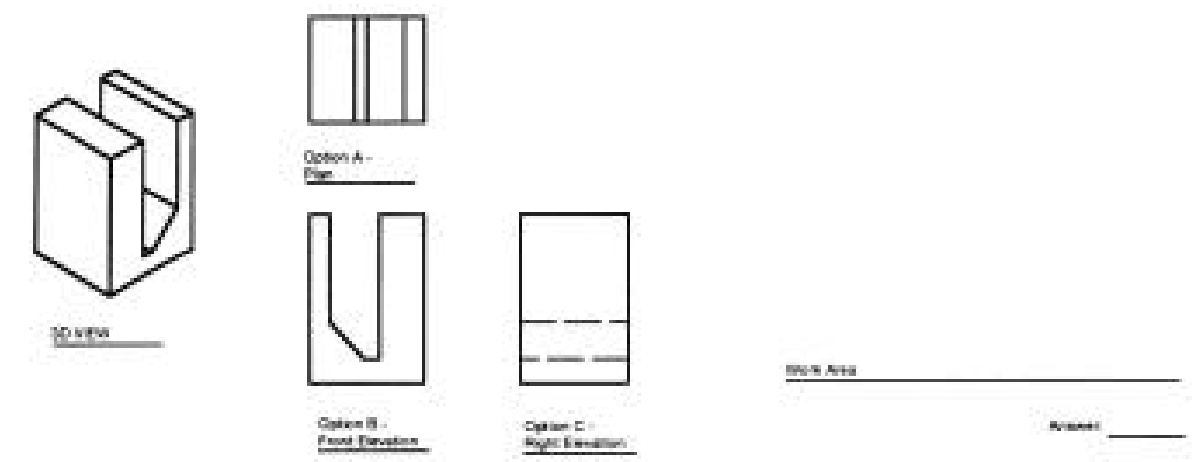

(1) 34

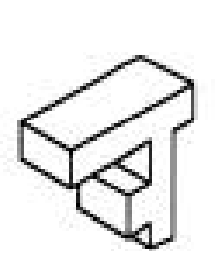

yoven
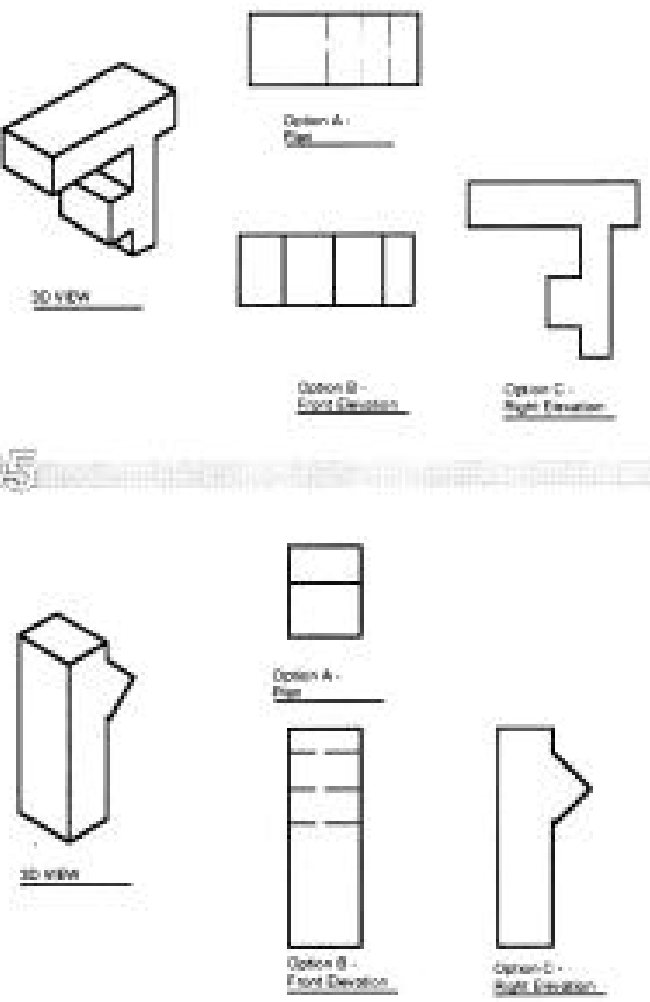

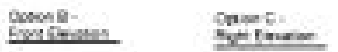

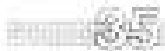

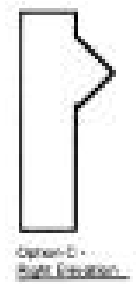

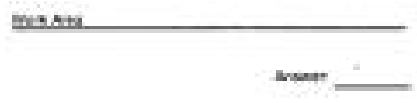




\section{APPENDIX I}

Correlation Matrix 
Correlations Between Dimensions of Judgment

\begin{tabular}{lccl}
\hline & APPROPRIATENESS & CREATIVITY & NOVELTY \\
APPROPRIATENESS & 1.00 & 0.770 & 0.866 \\
& & 0.000 & 0.000 \\
CREATIVITY & 0.770 & 1.00 & 0.898 \\
& 0.000 & & 0.000 \\
NOVELTY & 0.866 & 0.898 & 1.00 \\
& 0.000 & 0.000 & \\
\hline
\end{tabular}

Cell Contents: Correlation

P-Value 


\section{APPENDIX J}

Representative Student Projects 


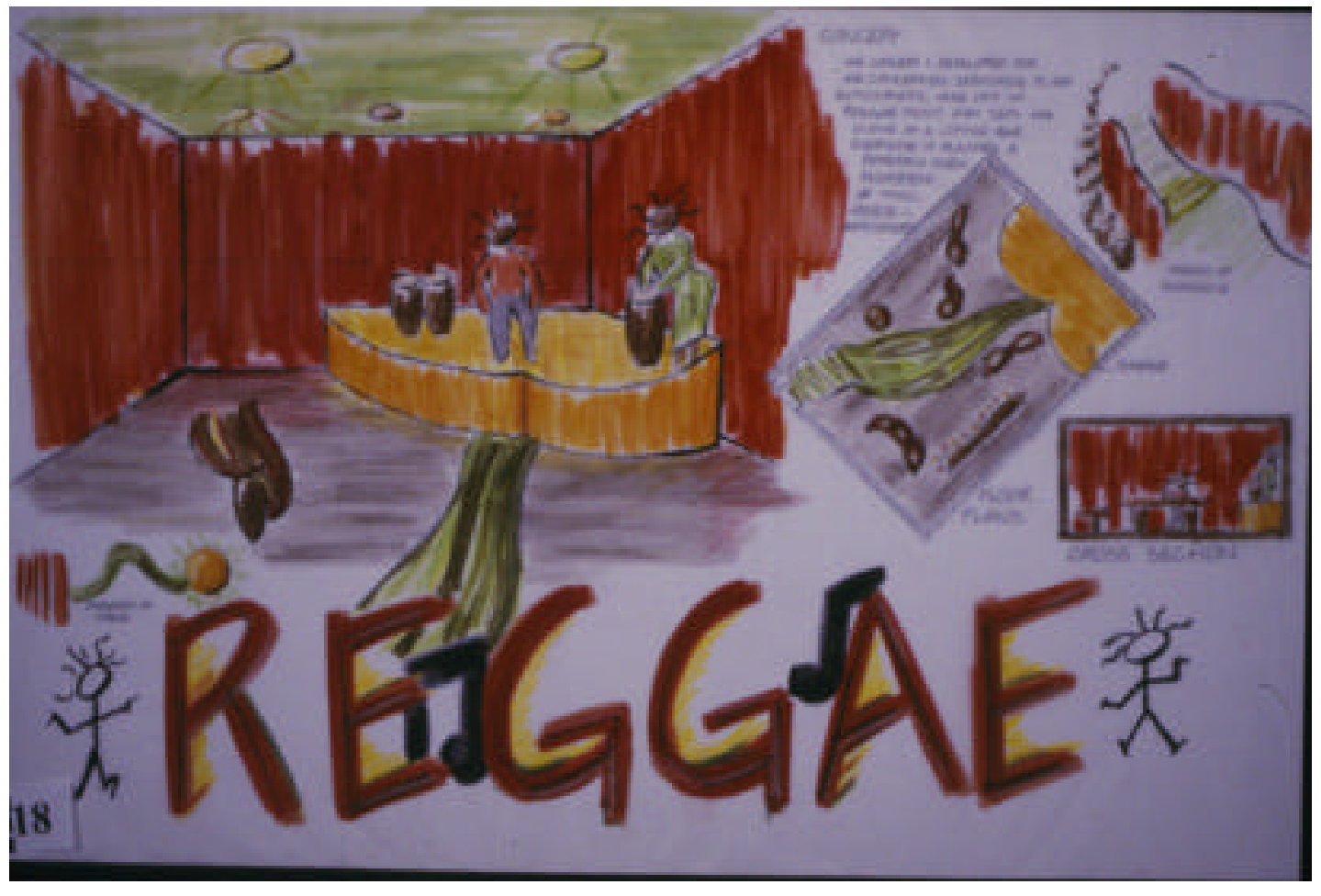

Student Project No. 18 


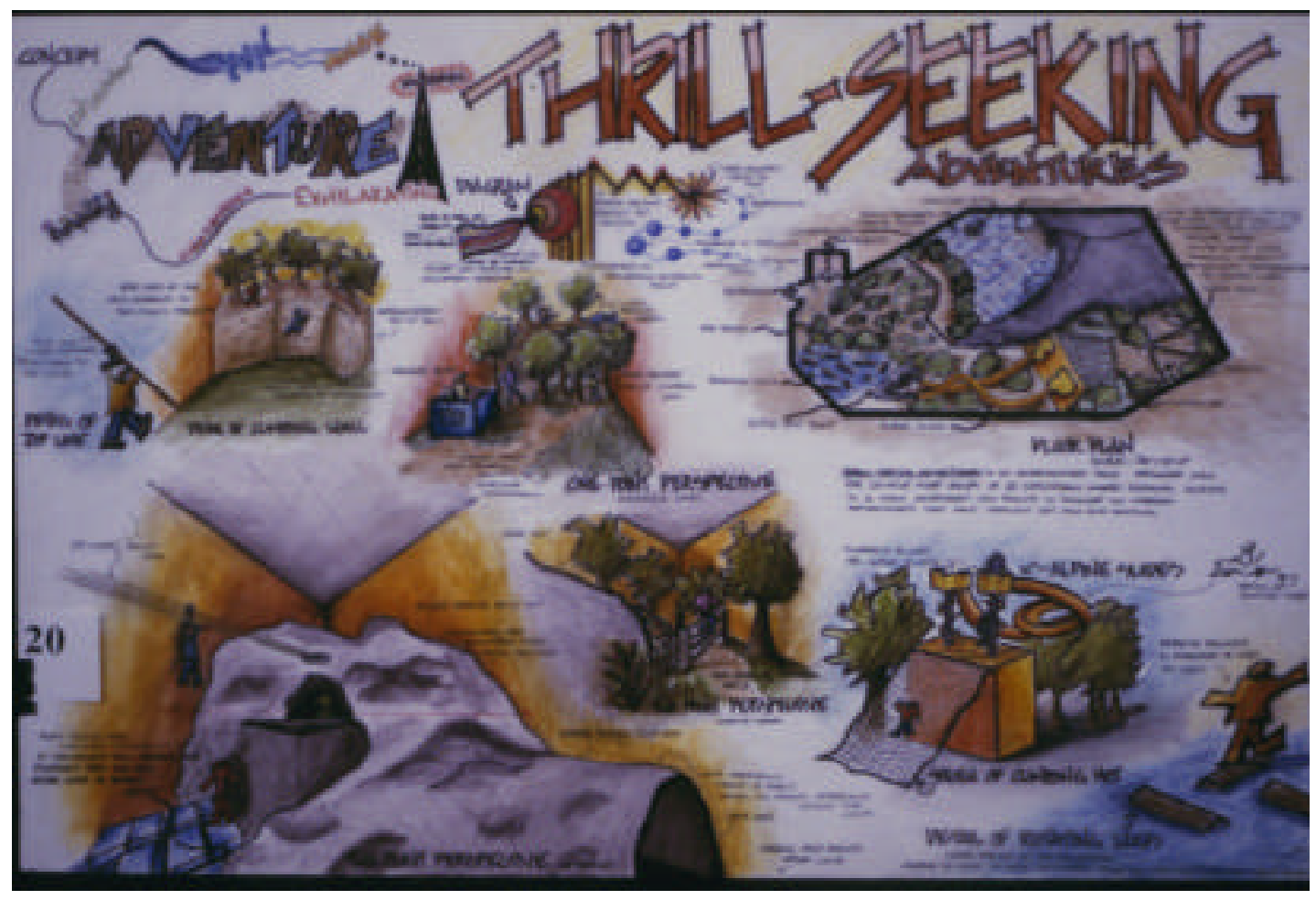

Student Project No. 20 


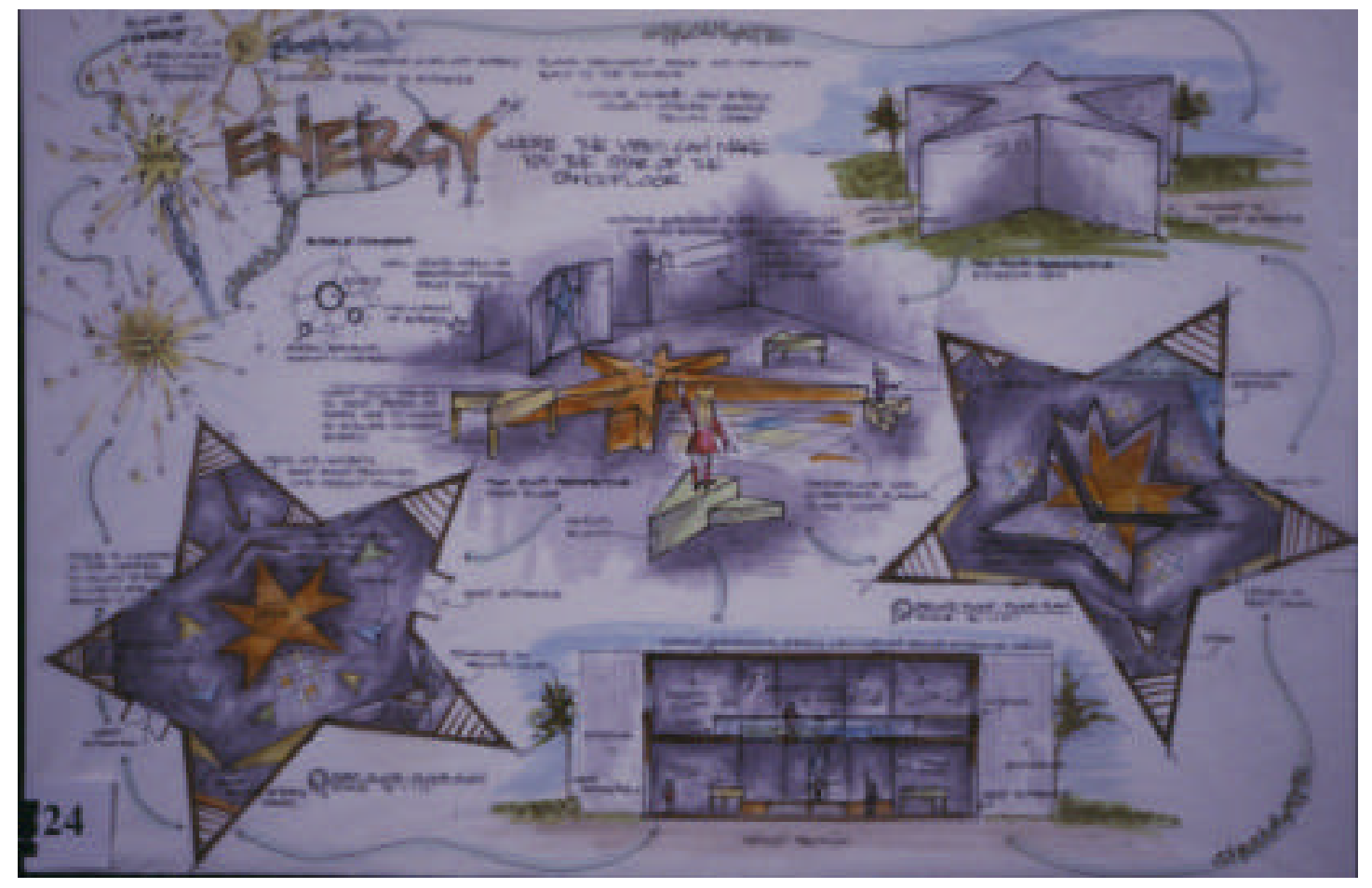

Student Project No. 24 


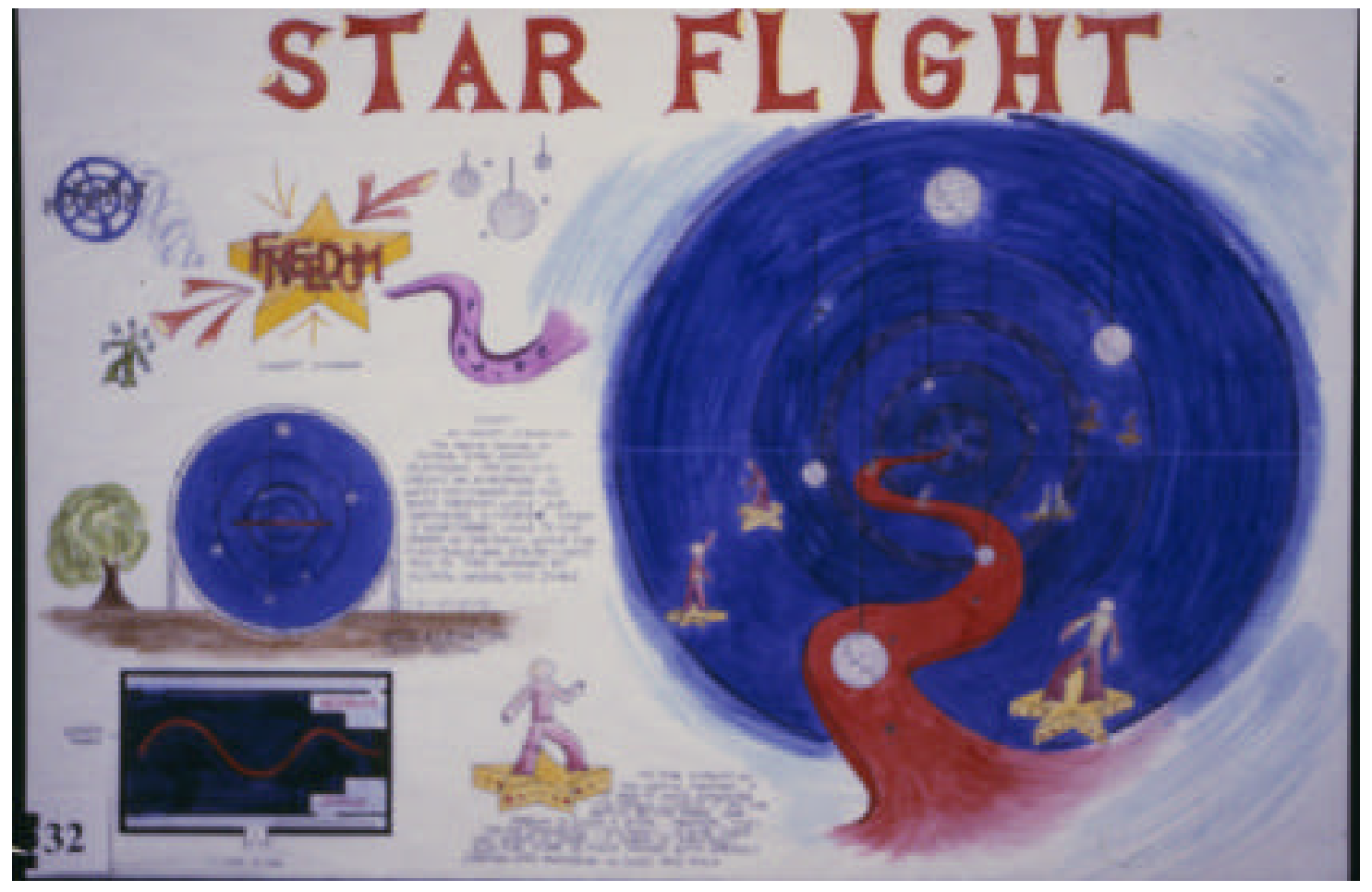

Student Project No. 32 


\section{VITA}

April Diane Allen, daughter of Champ Willis Allen and Bertha Mae Giles Allen, was born in Rutherfordton, North Carolina on April 5, 1949. She graduated from East Rutherford High School in 1967 and attended Western Carolina University from 1967 to 1969 . She completed her Bachelor of Science degree in Home Economics with a Concentration in Housing and Interior Design at Appalachian State University in 1979 where she graduated Magna Cum Laude and was the Honor Marshall for the College of Fine and Applied Arts.

From 1979 to 1997 , April was employed in the field of interior design. She worked in commercial and residential design with the major focus of her work in store planning for the furniture manufacturing industry. In 1996 she passed the NCIDQ, the National Council for Interior Design Qualification, examination. In 1997 she enrolled as a graduate student at the University of North Carolina at Greensboro in the Department of Housing and Interiors where she worked as a graduate teaching assistant. In 1998 she transferred to the Department of Near Environments at Virginia Polytechnic Institute and State University also working as a graduate teaching assistant within the department.

In August 1999 she accepted a teaching position in the Department of Interior Design and Fashion at Radford University where she taught full-time while completing her thesis.

April has been inducted into the following honorary fraternities: Alpha Chi and Gamma Beta Phi.

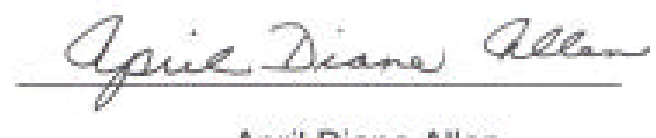

April Diane Allen 